\title{
Genetic variants modulate gene expression statin response in human lymphoblastoid cell lines
}

\author{
Elizabeth Theusch ${ }^{1}$, Yii-Der I. Chen², Jerome I. Rotter ${ }^{3}$, Ronald M. Krauss ${ }^{4}$ and Marisa W. Medina ${ }^{1 *}$ (D)
}

\begin{abstract}
Background: Statins are widely prescribed to lower plasma low-density lipoprotein cholesterol levels. Though statins reduce cardiovascular disease risk overall, statin efficacy varies, and some people experience adverse side effects while on statin treatment. Statins also have pleiotropic effects not directly related to their cholesterollowering properties, but the mechanisms are not well understood. To identify potential genetic modulators of clinical statin response, we looked for genetic variants associated with statin-induced changes in gene expression (differential eQTLs or deQTLs) in lymphoblastoid cell lines (LCLs) derived from participants of the Cholesterol and Pharmacogenetics (CAP) $40 \mathrm{mg} /$ day 6-week simvastatin clinical trial. We exposed CAP LCLs to $2 \mu \mathrm{M}$ simvastatin or control buffer for $24 \mathrm{~h}$ and performed polyA-selected, strand-specific RNA-seq. Statin-induced changes in gene expression from 259 European ancestry or 153 African American ancestry LCLs were adjusted for potential confounders prior to association with genotyped and imputed genetic variants within $1 \mathrm{Mb}$ of each gene's transcription start site.
\end{abstract}

Results: From the deQTL meta-analysis of the two ancestral populations, we identified significant cis-deQTLs for 15 genes (TBC1D4, MDGA1, CHI3L2, OAS1, GATM, ASNSD1, GLUL, TDRD12, PPIP5K2, OAS3, SERPINB1, ANKDD1A, DTD1, CYFI $P 2$, and GSDME), eight of which were significant in at least one of the ancestry subsets alone. We also conducted eQTL analyses of the endogenous (control-treated), statin-treated, and average of endogenous and statin-treated LCL gene expression levels. We identified eQTLs for approximately 6000 genes in each of the three (endogenous, statin-treated, and average) eQTL meta-analyses, with smaller numbers identified in the ancestral subsets alone.

Conclusions: Several of the genes in which we identified deQTLs have functions in human health and disease, such as defense from viruses, glucose regulation, and response to chemotherapy drugs. This suggests that DNA variation may play a role in statin effects on various health outcomes. These findings could prove useful to future studies aiming to assess benefit versus risk of statin treatment using individual genetic profiles.

Keywords: Statin, Expression quantitative trait locus (eQTL), Gene-environment interaction, RNA-sequencing, Lymphoblastoid cell line

\footnotetext{
*Correspondence: marisa.medina@ucsf.edu

'Department of Pediatrics, University of California San Francisco, Oakland, CA, USA

Full list of author information is available at the end of the article
}

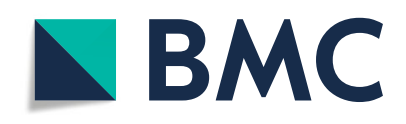

(c) The Author(s). 2020 Open Access This article is licensed under a Creative Commons Attribution 4.0 International License, which permits use, sharing, adaptation, distribution and reproduction in any medium or format, as long as you give appropriate credit to the original author(s) and the source, provide a link to the Creative Commons licence, and indicate if changes were made. The images or other third party material in this article are included in the article's Creative Commons licence, unless indicated otherwise in a credit line to the material. If material is not included in the article's Creative Commons licence and your intended use is not permitted by statutory regulation or exceeds the permitted use, you will need to obtain permission directly from the copyright holder. To view a copy of this licence, visit http://creativecommons.org/licenses/by/4.0/. The Creative Commons Public Domain Dedication waiver (http://creativecommons.org/publicdomain/zero/1.0/) applies to the data made available in this article, unless otherwise stated in a credit line to the data. 


\section{Background}

Statins are a class of drugs widely used to lower circulating low-density lipoprotein cholesterol (LDL-C) levels and reduce cardiovascular disease risk [1]. Statins can have other beneficial pleiotropic effects, such as reducing inflammation [2]. However, statin treatment can also have adverse effects, such as myopathy [3] or new-onset diabetes [4]. Though the general mechanism by which statins lower LDL-C is well established [5], there is considerable inter-individual variability in statin efficacy that remains largely unexplained by genetic [6-8] and other [9] factors. In addition, there is much still to be learned about the mechanisms by which statins exert their pleiotropic and adverse effects and how genetic variation impacts statin response at the individual level.

Genetic variants associated with human traits in genome-wide association studies (GWAS) are enriched for those also associated with gene expression levels (expression quantitative trait loci or eQTLs) [10]. Consequently, eQTL datasets contributed by GTEx [11] and others have been instrumental toward improving the annotation of GWAS in recent years, helping to assign candidate causal genes to associated loci. Historically, pharmacogenomics GWAS have not been as wellpowered as other traits, since participants need pretreatment and on-treatment phenotype measurements, limiting the available participant pool [12]. Thus, annotation of sub-genome wide loci from pharmacogenomic GWAS using eQTL data could help to filter signal from noise and identify candidate genes for study.

Environmental exposures can alter the relationships between genetic variants and phenotypes, creating gene-environment interactions $(\mathrm{GxE})$. For instance, drug exposure could differentially change gene expression levels in individuals with different genotypes for a particular "differential eQTL" genetic variant. In contrast to the large number of "endogenous" eQTL studies already conducted in human cells and tissues in their natural, untreated state, there have been a limited number of differential eQTL studies to date, including studies of exposures to immune system stimulation [13-16], UV light [17], drugs [18], or a variety of environmental factors [19] .

In this study, we used a human lymphoblastoid cell line (LCL) statin response model system to identify candidate genetic modulators of clinical statin response. Previous work has demonstrated that statins elicit a strong transcriptional response [20] and that genetic modulators of statin-induced changes in LCL gene structure [21] and expression levels [18] are associated with clinical statin efficacy and adverse events, respectively. Here, we identify additional genetic variants associated with the statin response of clinically important genes that may play a role in statin response.

\section{Results}

\section{Endogenous eQTLs}

We first correlated genetic variation with endogenous gene expression levels to identify eQTLs in 259 Cholesterol and Pharmacogenetics (CAP) European American participant LCLs and in 153 CAP African American LCLs separately. To correct for testing multiple variants per gene, we conducted 100,000 permutations in FastQTL [22]. The most significant eQTL per gene was retained prior to false discovery rate (FDR) adjustment for the number of genes tested. In European American LCLs, 5456 of 13,841 genes tested (39\%) were eGenes (genes with at least one significant eQTL) at an FDR of 5\% (Additional File 1: Table S1). Similarly, in African American LCLs, 3389 of 13,817 genes tested (25\%) were eGenes at an FDR of 5\% (Additional File 2: Table S2). Finally, we used METAL [23] to conduct a fixed effects meta-analysis of the eQTL results from the two ethnic subsets, identifying 6065 (44\%) eGenes at a threshold of $p<1 \times 10^{-5}$ (Additional File 3: Table S3). Of these, a minority, 104, had a heterogeneity level of significance of $p<0.0001$, suggesting a difference in effect size between the two ethnic groups.

\section{Statin-treated eQTLs}

Similarly, we correlated genetic variation with gene expression levels in statin-treated LCLs. Using this approach, 5414 of 13,841 genes tested (39\%) were eGenes $(F D R=5 \%)$ in European American LCLs (Additional File 4: Table S4), while 3298 of 13,817 genes tested $(24 \%)$ were eGenes $(\mathrm{FDR}=5 \%)$ in African American LCLs (Additional File 5: Table S5). In the meta-analysis of both ethnic subsets, we identified 5978 eGenes (43\%) at $p<1 \times 10^{-5}$ (Additional File 6: Table S6). 85 of these were ethnically heterogeneous, with a heterogeneity $p<0.0001$. Overall, there was a comparable but slightly smaller number of statin-treated eQTLs than endogenous eQTLs identified from the same cell lines. Over $90 \%$ of statin-treated eGenes were also endogenous eGenes (Fig. 1 [24]).

\section{Average eQTLs}

Since the majority of eQTL relationships were similar in the endogenous and the statin-treated state in LCLs, we reasoned that averaging control-treated LCL gene expression levels with the corresponding $2 \mu \mathrm{M}$ simvastatin-treated LCL gene expression levels would increase power to detect eQTLs due to the reduction in measurement error [18]. Indeed, we identified more eQTLs using the average of the control- and statintreated LCL gene expression levels compared to the control-treated or statin-treated gene expression levels alone. In European American LCLs, we identified 5870 (42\%) eGenes with significant average eQTLs (FDR = 5\%; 


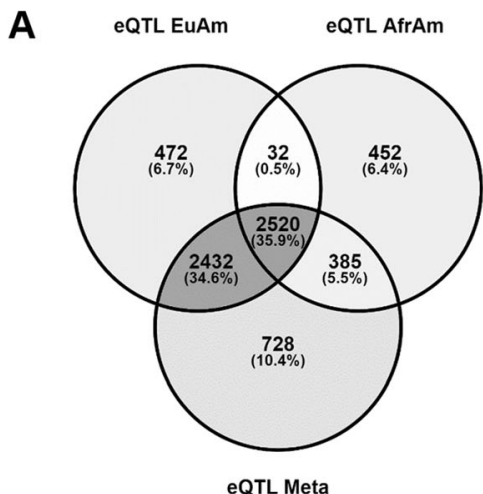

C

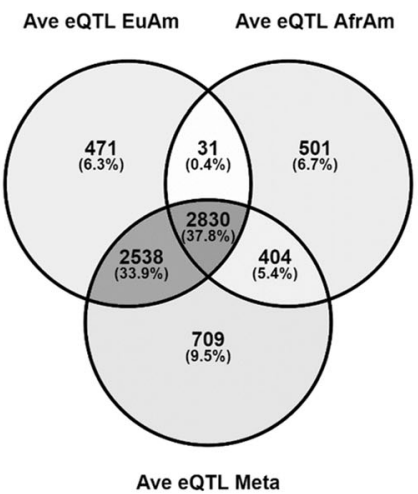

E Statin eQTL EUAm Statin EQTL AfrA

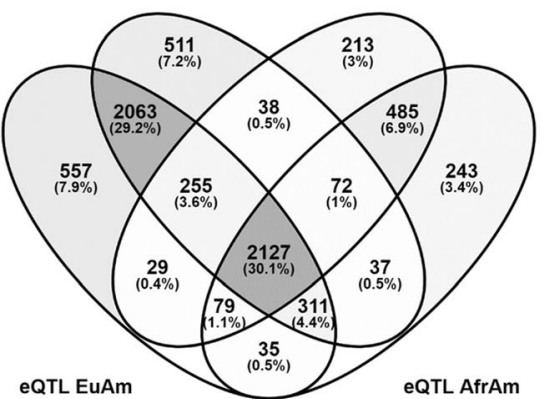

B

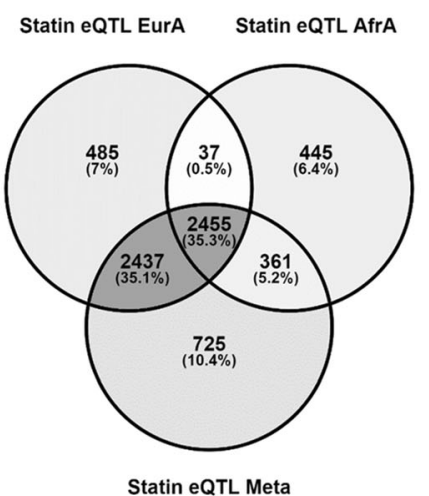

D

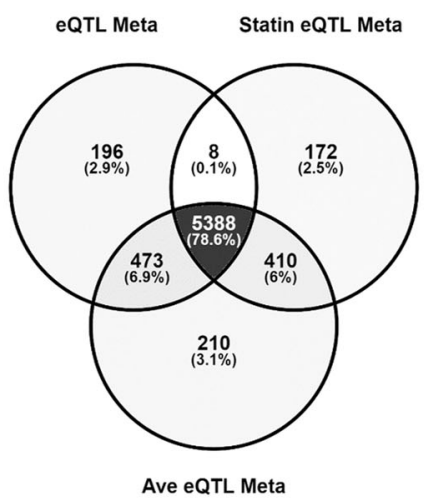

$\mathbf{F}$

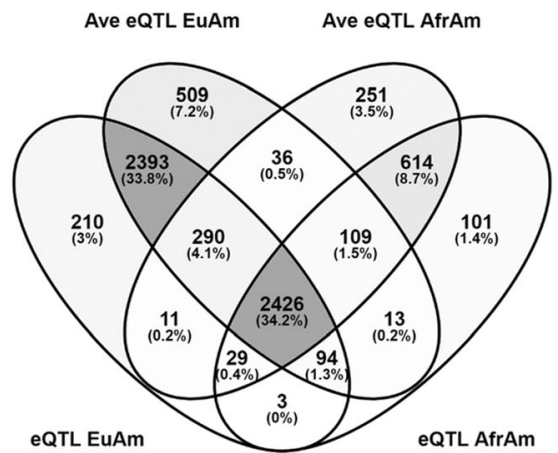

Fig. 1 Venn diagrams of overlap between endogenous, statin-treated, and average eQTLs from the meta-analysis and ancestry subsets. Overlap of (a) endogenous (b) statin-treated and (c) average eQTL eGenes between European and African American ancestry subsets and the metaanalysis. The majority of eQTLs identified are not ancestry specific, and the numbers of eGenes identified increases with sample size. $\mathbf{d}$ Overlap of eGenes from endogenous, statin-treated, and average eQTL meta-analyses. Statin treatment did not significantly change numbers of eGenes, but averaging endogenous and statin-treated expression levels offered increased power for eQTL analysis. Overlap of European and African American ancestry endogenous eQTLs with (e) statin-treated and (f) average eQTLs. Venn diagrams were created in Venny 2.1 [24]

Additional File 7: Table S7), while in African American LCLs we identified 3766 (27\%) eGenes (Additional File 8: Table S8). In the meta-analysis, there were $6481(47 \%)$ eGenes $\left(p<1 \times 10^{-5}\right)$, 115 with heterogeneity $p<0.0001$ (Additional File 9: Table S9). $78.6 \%$ of eGenes overlapped between the endogenous, statin-treated, and average eQTL meta-analyses, as shown in Fig. 1 [24].

\section{European American differential eQTLs}

Using statin-induced changes in LCL gene expression and imputed genotype data from 259 CAP participants of European ancestry, we identified genetic variants significantly associated with the statin response (i.e. change in transcript levels) of eight genes (FDR 5\%; Table 1, Fig. 2a-e \& Fig. 3a-c). For six of these genetic variants, the endogenous eQTL relationship with gene expression levels was stronger than the differential eQTL relationship. For the remaining two deQTL genes, OAS1 and OAS3, we did not identify a strong endogenous eQTL in our dataset (Fig. 4a-e \& Fig. 5a-c). However, other studies have reported all eight of the deQTL variants to be eQTL 
Table 1 Significant lead deQTLs in European ancestry LCLS

\begin{tabular}{lllllllllll}
\hline Variant & Chr & BP & Gene & |Dist. to TSS| (bp) & Ref & Alt & Alt Freq. & Effect Size (Alt) & Nominal P & Beta Perm Q \\
\hline rs745527 & 1 & $111,745,975$ & CHI3L2 & 2581 & G & A & $48 \%$ & 0.73 & $4.8 E-16$ & $8.50 E-08$ \\
rs7134391 & 12 & $113,366,691$ & OAS1 & 22,108 & G & A & $63 \%$ & -0.73 & $1.9 E-14$ & $7.10 \mathrm{E}-07$ \\
rs1859329 & 12 & $113,376,452$ & OAS3 & 294 & C & T & $63 \%$ & -0.65 & $6.7 E-12$ & $9.90 E-05$ \\
rs507901 & 13 & $75,869,652$ & TBC1D4 & 186,599 & C & A & $57 \%$ & 0.63 & $7.3 E-11$ & $9.50 E-04$ \\
rs4711510 & 6 & $37,669,641$ & MDGA1 & 2558 & G & A & $50 \%$ & -0.54 & $3.5 E-10$ & 0.0034 \\
rs2237310 & 7 & $24,759,648$ & GSDME & 49,597 & A & C & $11 \%$ & 0.81 & 3.0 E-10 & 0.0034 \\
rs1684051 & 15 & $65,198,309$ & ANKDD1A & 5793 & G & C & $65 \%$ & -0.54 & 2.0 E-09 & 0.006 \\
rs1233291 & 2 & $190,690,951$ & ASNSD1 & 164,839 & G & C & $27 \%$ & -0.57 & $6.2 E-09$ & 0.016 \\
\hline
\end{tabular}

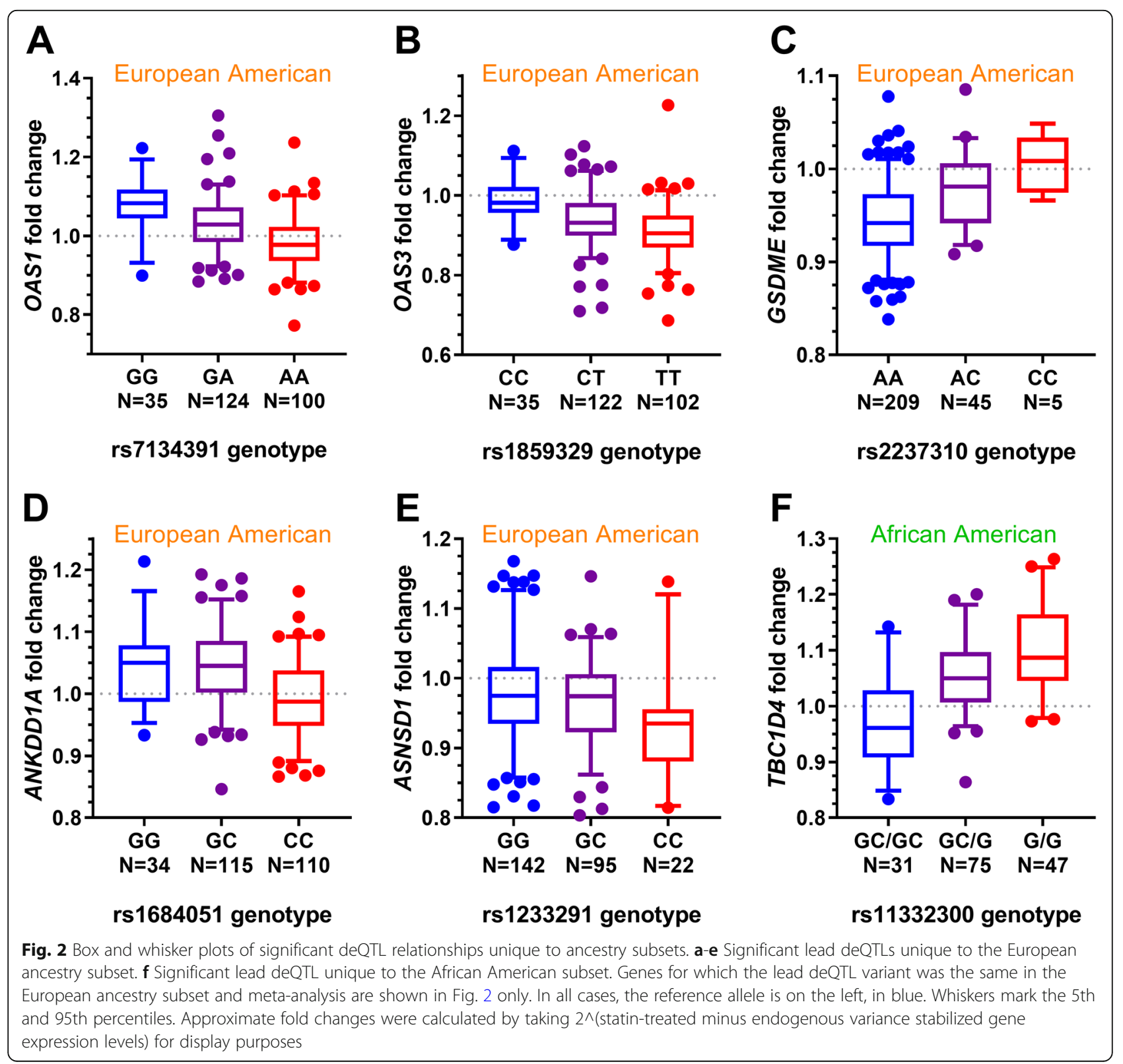



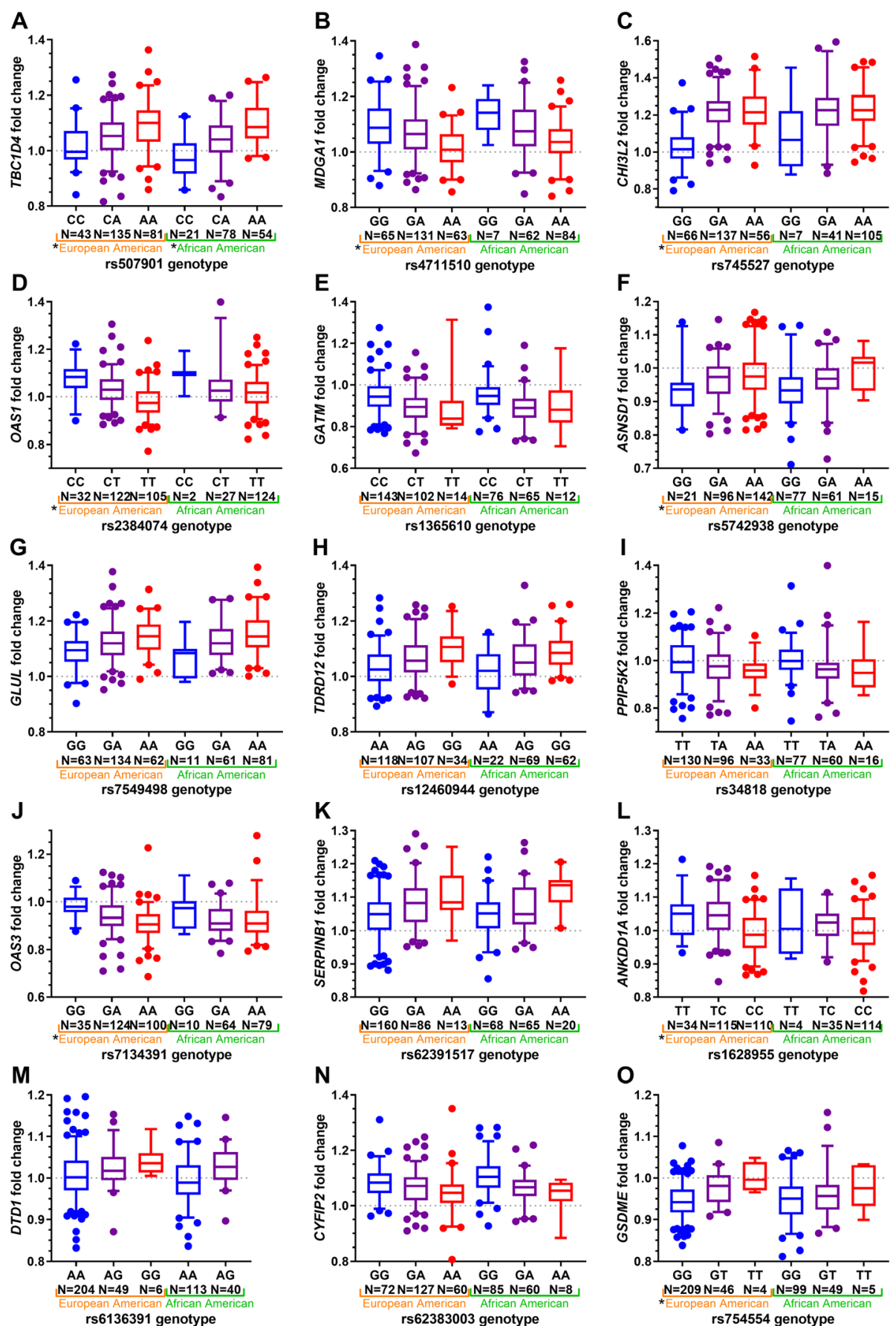

Fig. 3 Box and whisker plots of significant deQTLs from meta-analysis. Significant lead deQTLs from meta-analysis are shown in the European (left) and African American (right) subsets in each plot. Asterisks ${ }^{*}$ ) preceding ancestry subset names indicate deQTL relationships that are significant in that ancestry subset. In all cases, the reference allele is on the left, in blue. Whiskers mark the 5th and 95th percentiles. Approximate fold changes were calculated by taking $2^{\wedge}$ (statin-treated minus endogenous variance stabilized gene expression levels) for display purposes

variants in at least one cell or tissue type (Additional File 10: Table S10) [11, 25, 26].

$O A S 1$ and $O A S 3$ are adjacent to each other in the genome, and their lead deQTL variants are in strong linkage disequilibrium $\left(\mathrm{r}^{2}=0.97\right)$ in EUR (Fig. 6) [27]. They are also in LD with a known OAS1 splice site mutation $(\mathrm{rs} 10774671)$ in EUR $\left(\mathrm{r}^{2}=0.88\right)$ but not AFR $\left(\mathrm{r}^{2}<0.2\right)$ and were strongly $\left(p<10^{-50}\right)$ correlated with endogenous, but not statin-induced changes in, OAS1 splicing in the CAP European American LCLs (Fig. 7). 

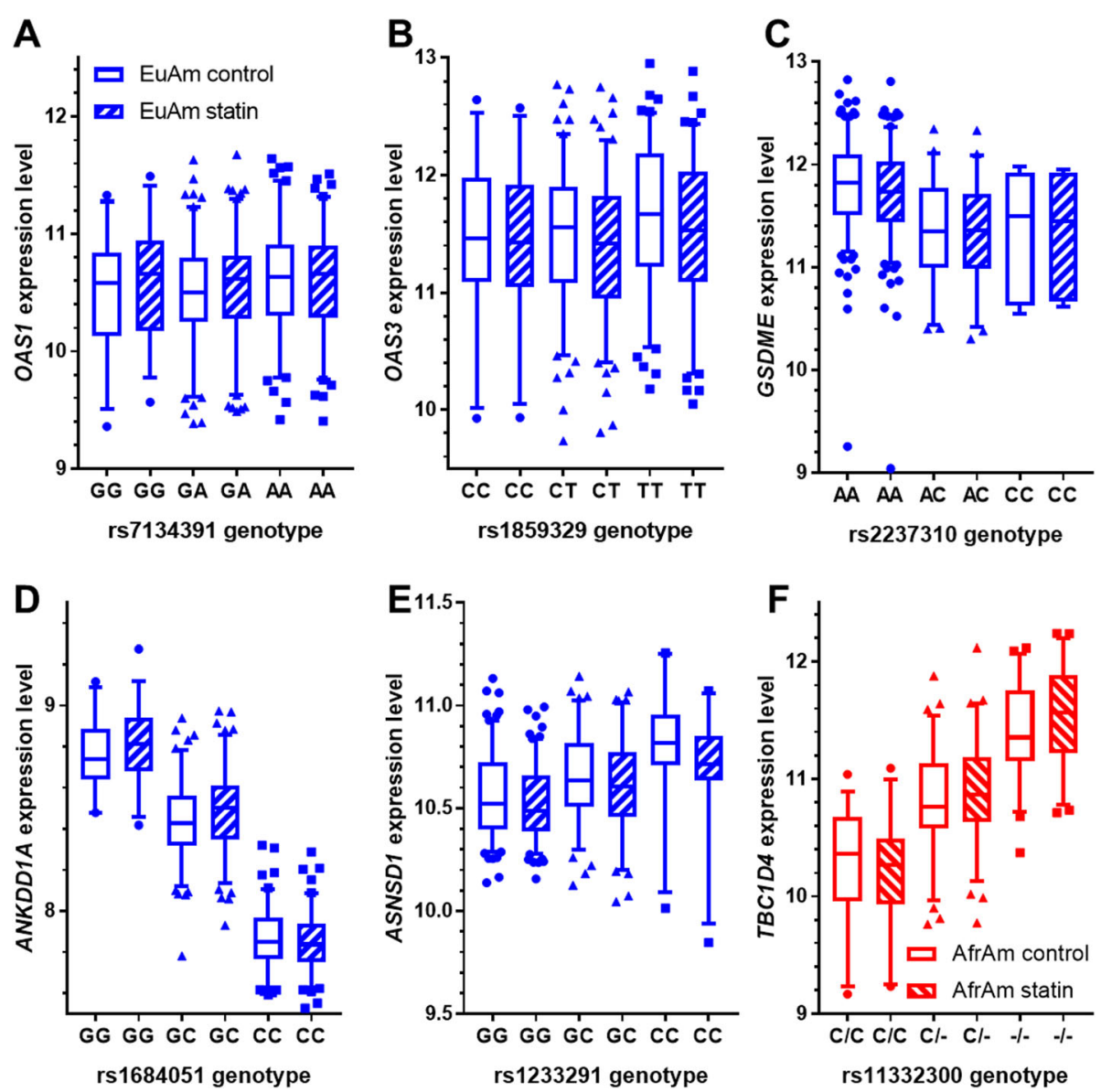

Fig. 4 Control and statin-treated gene expression levels split by deQTL genotype for lead deQTLs unique to ancestry subsets. a-e Significant lead deQTLs unique to the European ancestry subset. f Significant lead deQTL unique to the African American subset. Genes for which the lead deQTL variant was the same in the European ancestry subset and meta-analysis are shown in Fig. 5 only. In all cases, the reference allele is on the left. Whiskers mark the 5 th and 95 th percentiles. Approximate fold changes were calculated by taking $2 \wedge$ (statin-treated minus endogenous variance stabilized gene expression levels) for display purposes. Sample sizes match those in Fig. 2

\section{African American differential eQTL}

Similarly, we conducted a deQTL analysis in 153 CAP participants of African American ancestry. TBC1D4 was the only gene with a significant $(F D R=5 \%)$ deQTL in this population, and its most significant deQTL was rs11332300 (Table 2, Fig. 2f). Interestingly, rs11332300 and adjacent variants rs61960554 and rs7329261 in strong linkage disequilibrium $\left(r^{2}>0.98\right.$ in AFR and EUR) may be functional variants because they are located in a LCL enhancer element based on ChIP-seq data from the ENCODE project (Fig. 8) [28, 29]. These variants are also endogenous eQTLs for TBC1D4(Additional File 10: Table S10) $[11,25,26]$. These three variants were not imputed in the CAP European Americans using the Haplotype Reference Consortium reference panel, but the fourth most significant variant in more modest $\mathrm{LD}\left(\mathrm{r}^{2}=0.58\right.$ in AFR and 0.92 in EUR) with the first three, rs507901, was found in both datasets.

\section{Differential eQTL meta-analysis}

Significant deQTLs for 15 genes were identified in the meta-analysis $\left(p<5 \times 10^{-9}\right.$; Table 3 , Fig. 3), and these included deQTLs for all eight of the genes identified in the ethnic subset analyses. All of these variants were within $200 \mathrm{~kb}$ of their target genes, though the search space was five times larger. Four of the 15 significant deQTL loci (CHI3L2, OAS1, OAS3, and GSDME) showed evidence for ethnic heterogeneity in effect sizes, with stronger effects seen in individuals of European ancestry.

All 15 variants were also eQTLs for the deQTL genes in at least one cell or tissue type (Additional File 10: Table S10) [11, 25, 26], but the deQTLs for OAS1, OAS3 and GATM were not significant eQTLs in the CAP LCLs from our study (Table 4, Fig. 5). Though statin treatment enhanced the eQTL relationship for most deQTLs (8 out of 12), it dampened the eQTL relationship for 


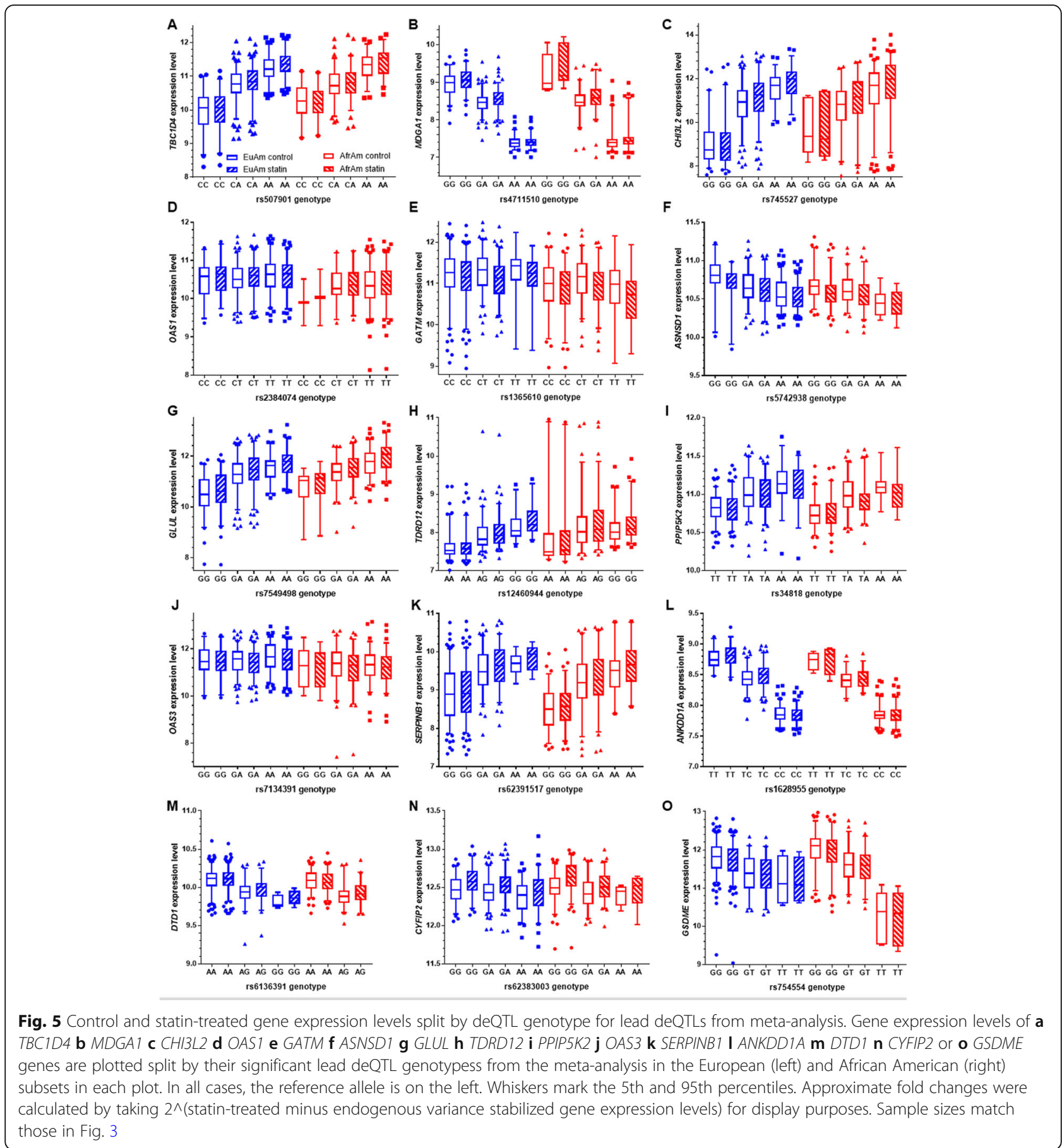

others (e.g. ASNSD1), which is reflected in the weaker statin eQTL association compared to the eQTL association (Table 4) and the different directionality of the deQTL and eQTL associations (Figs. 3 \& 5). For example, the association of rs5742938 genotype with ASNS $D 1$ statin-treated expression levels was more modest $\left(P=1.6 \times 10^{-26}\right)$ than its association with endogenous expression levels $\left(P=2.1 \times 10^{-47}\right)(p=0.04$ and $p=0.08$ for difference between endogenous and statin eQTL correlations using Fisher's $\mathrm{r}$ to $\mathrm{z}$ transformation in European and African American subsets, respectively), and the alternate "C" allele of rs5742938 was correlated with higher endogenous and statin-treatedASNSD1 levels but with greater reductions in ASNSD1 expression with statin treatment.

Of note, a deQTL for GATM was previously identified using gene expression array data from a partially overlapping sample set of 480 European American CAP 


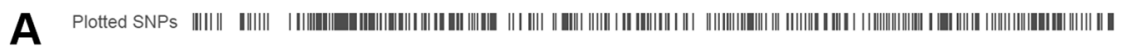

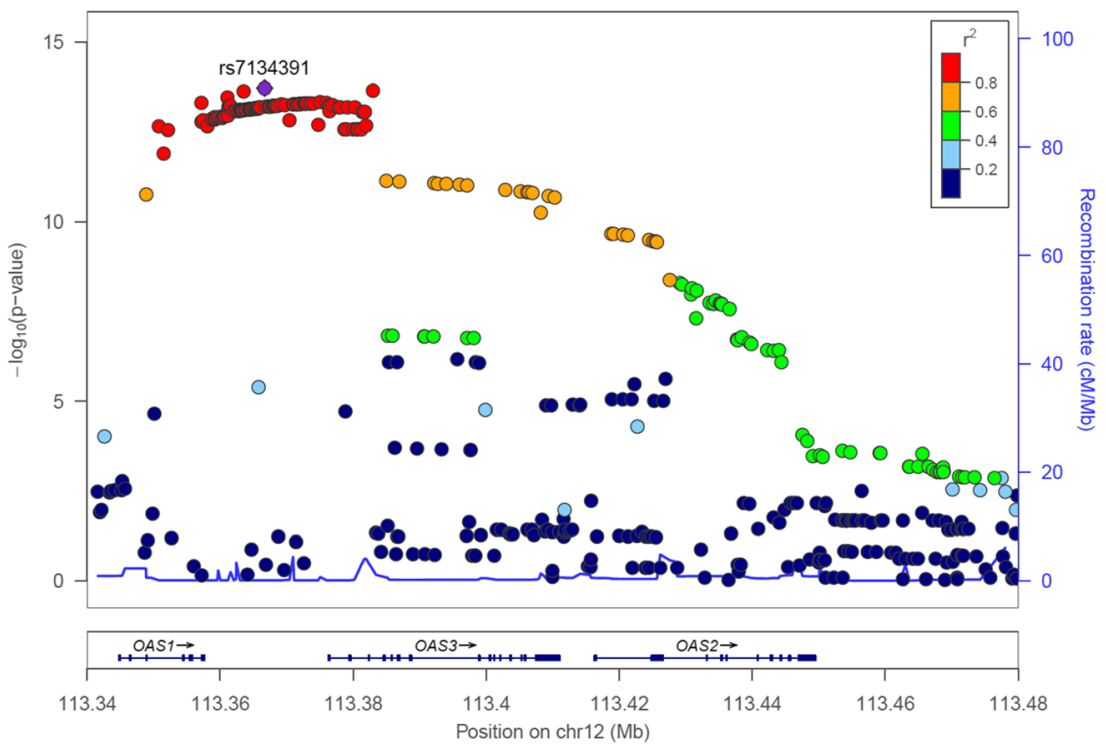

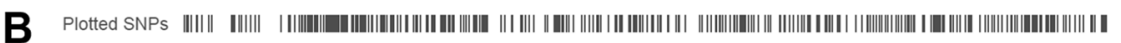

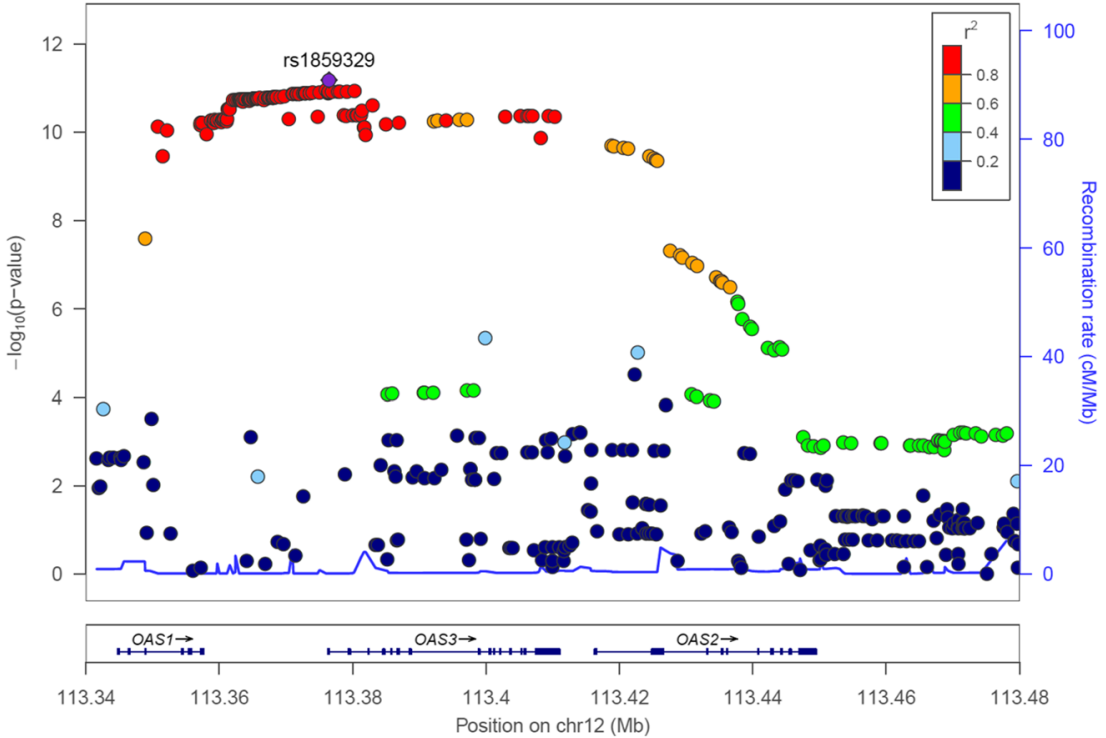

Fig. 6 LocusZoom plots of (a) OAS1 and (b) OAS3 deQTL associations in European ancestry subset. Linkage disequilibrium information is derived from EUR individuals in the November 20141000 Genomes data release

LCLs [18]. (211 European ancestry LCLs were used in both studies.) The lead deQTL variant in that study, rs9806699, is in moderately strong linkage disequilibrium with our lead deQTL variant, rs1365610, in EUR $\left(\mathrm{r}^{2}=0.768\right)$ but not AFR $\left(\mathrm{r}^{2}=0.266\right)$ populations [27] (Fig. 9). rs1365610 could itself be a functional variant based on its location in a collection of regulatory elements just upstream of an alternate GATM first exon (Fig. 10) [28, 29].

The lead deQTL for GSDME (aka DFNA5), rs754554, is a missense variant that is located in an LCL enhancer element based on ENCODE ChIP-seq data (Fig. 11) [28, 29], while the lead deQTL variant from the European American subset analysis, rs2237310, lacks this level of support for functionality. This is also reflected by an improved RegulomeDB score for rs754554 (score of $1 \mathrm{f}$ reflecting a likelihood that the variant affects transcription factor binding and is an eQTL) compared to rs2237310 (score of 6 showing minimal binding evidence), a phenomenon that was also observed for lead deQTL variants for other genes, such as ANKDD1A (score of $1 \mathrm{f}$ for rs1628955 from meta-analysis versus 5 


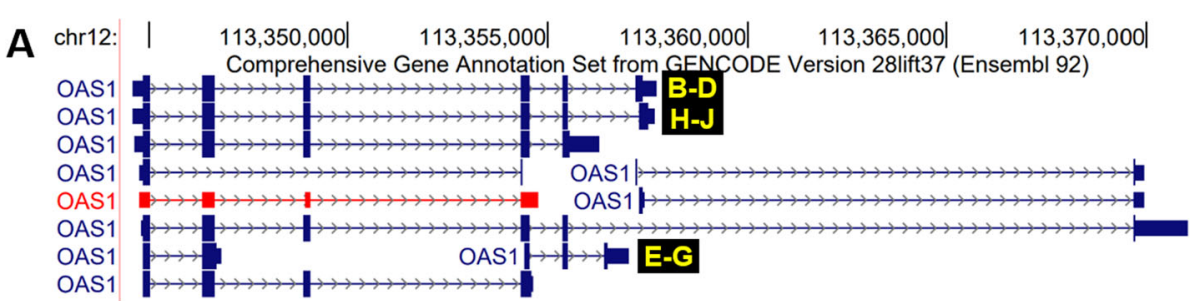

B

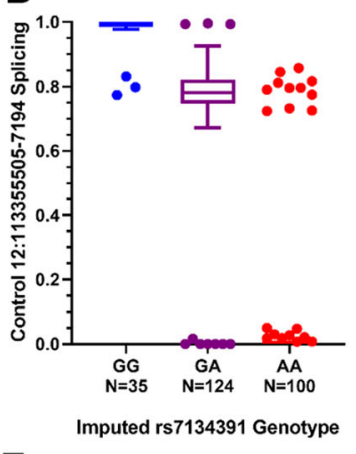

E

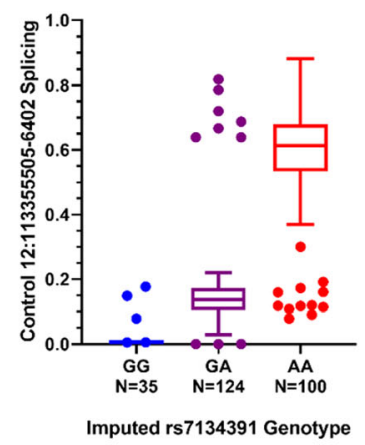

$\mathbf{H}$

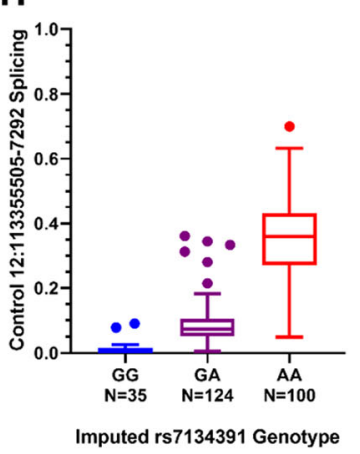

C

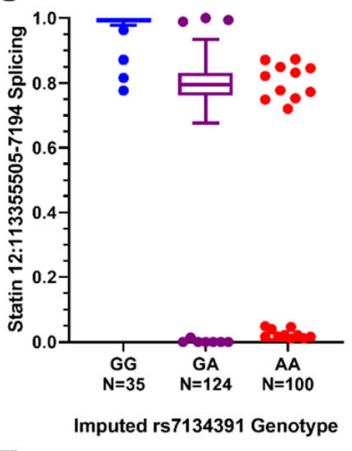

F

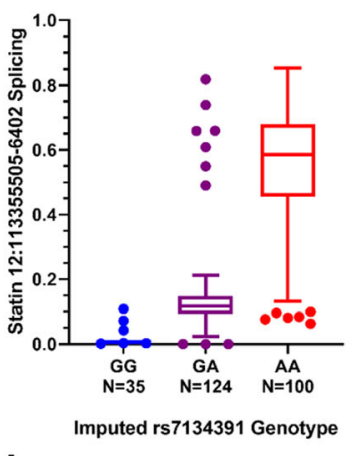

I

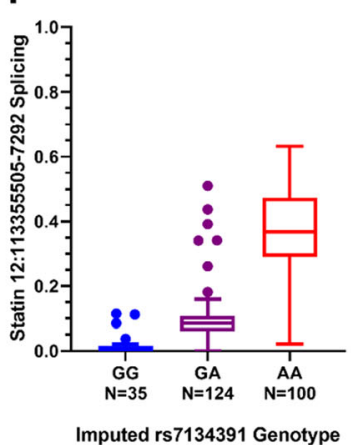

D

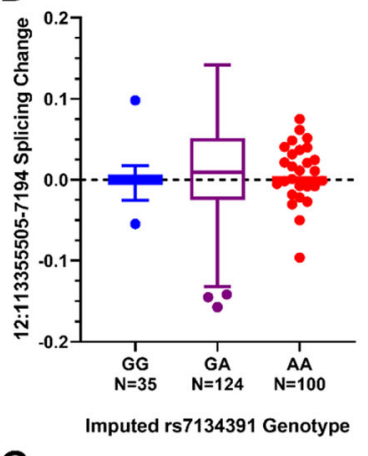

G

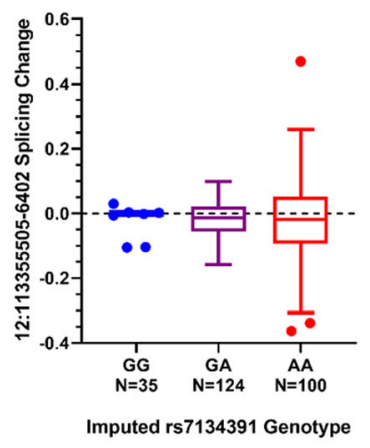

$\mathbf{J}$

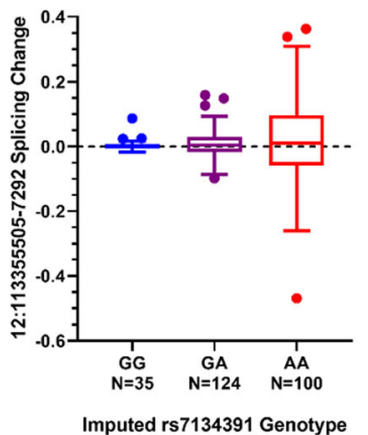

Fig. 7 Endogenous, statin-treated, and statin-induced changes in OAS1 splicing by deQTL genotype in European ancestry subset. a OAS1 annotated isoforms. For three abundant splice isoforms with introns beginning at hg19 chr12:113355505 (p46:b-d, unnamed isoform: e-g, p48:h$\mathbf{j})$, the proportion of each isoform in control- and statin-treated European ancestry LCLs was calculated using junction-spanning read fractions. Isoform fractions in $(B, E, H)$ control- and $(C, F, I)$ statin-treated $L C L$ s as well as the $(D, G, J)$ statin-induced changes in these isoform fractions were plotted by European ancestry lead OAS1 deQTL (rs7134391) imputed genotypes in Tukey box and whisker plots. Since genotypes were imputed, some of the outlying points may be genotype assignment errors

for rs1684051 from European ancestry subset) [30]. Similar to the GATM deQTL results, this illustrates the utility of adding the African American to the European American data.

\section{Discussion}

In this study, we identify genetic variants ("differential eQTLs") that influence the statin response of 15 genes in lymphoblastoid cell lines from European American 
Table 2 Top deQTLs in African American ancestry LCLs

\begin{tabular}{lllllllllll}
\hline Variant & Chr & BP & Gene & |Dist. to TSS| (bp) & Ref & Alt & Alt Freq. & Effect Size (Alt) & Nominal P & Beta Perm Q \\
\hline rs11332300 & 13 & $75,874,521$ & TBC1D4 & 181,730 & GC & C & $55 \%$ & 0.77 & $1.41 \mathrm{E}-12$ & $2.6 \mathrm{E}-04$ \\
rs61960554 & 13 & $75,874,524$ & TBC1D4 & 181,727 & T & C & $55 \%$ & 0.77 & $1.47 \mathrm{E}-12$ & N/A \\
rs7329261 & 13 & $75,874,528$ & TBC1D4 & 181,723 & T & C & $55 \%$ & 0.77 & $1.47 \mathrm{E}-12$ & N/A \\
rs507901 & 13 & $75,869,652$ & TBC1D4 & 186,599 & C & A & $60 \%$ & 0.71 & $1.18 \mathrm{E}-09$ & N/A \\
\hline
\end{tabular}

and African American CAP study participants. We also detect endogenous, statin-treated, and average eQTLs for about 6000 genes in the same population of LCLs.

In our eQTL analyses, we identify substantially more eGenes than a study [25] of a comparable number of LCLs (> 6000 vs. $<4000$ eGenes identified) and we identify approximately the proportion of eGenes observed in GTEx tissues with this sample size [11], demonstrating the robustness of our data and analysis methods. In addition, the average eQTL analysis yields an additional 620 associations that are not identified by the endogenous eQTL meta-analysis, illustrating the utility of repeat measures to increase power when sample sizes are limited. Furthermore, 104 of the endogenous eQTLs we identify in the trans-ethnicmeta-analysis have heterogeneous effects between LCLs of European and African American ancestry, indicating a small subset of endogenous eQTL relationships exhibit ethnic heterogeneity.

The 15 deQTLs all share several properties that support their validity. First, they are close to the transcription start site of the target gene. Despite considering all variants $1 \mathrm{Mb}$ up- and downstream of the TSS, they are all within $200 \mathrm{~kb}$. Second, they all show consistent directionality between the European American and African American ethnic groups, though there is some heterogeneity in effect sizes between ethnic groups for four of the deQTLs. Third, they are all also endogenous eQTLs in at least one cell or tissue type in published studies $[11,25,26]$. Most, but not all, are endogenous eQTLs in the CAP LCLs.

In contrast to the thousands of eQTLs we identify in these 412 LCLs, we only find a modest 15 deQTLs. This highlights the large sample size necessary to detect relatively subtle GxE interactions with sufficient power. The modest number of deQTLs identified is also consistent with the handful of associated genetic loci identified in GWAS studies of lipid statin response [8] compared to the hundreds of loci associated with plasma lipids to date $[31,32]$. Together, these findings suggest that the DNA-drug interaction might only be a minor contributor to inter-individual variation in drug response.

Some of the deQTL findings may be specific to LCLs or blood, while others are likely to be more broadly relevant to other tissues. Most of the deQTL variants have

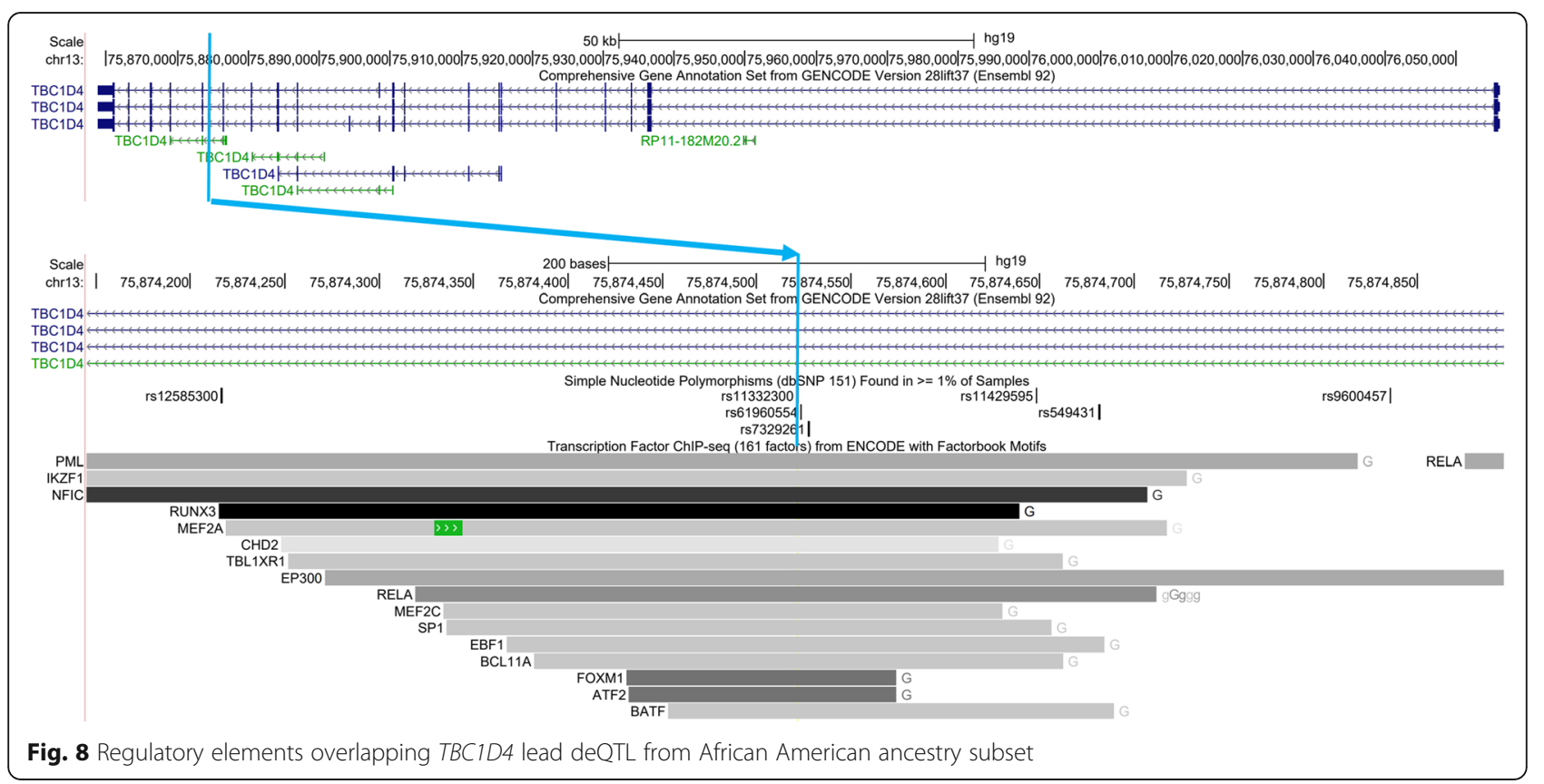


Table 3 Lead deQTLs from meta-analysis with heterogeneity statistics

\begin{tabular}{lllllllllll}
\hline Marker & Chr & BP & Gene & |Dist. to TSS| (bp) & Alt Dir & Meta P & EurAm P & AfrAm P & Het ISq & Het PVal \\
\hline rs507901 & 13 & $75,869,652$ & TBC1D4 & 186,599 & ++ & $7.3 \mathrm{E}-19$ & $7.3 \mathrm{E}-11$ & $1.2 \mathrm{E}-09$ & 0 & 0.39 \\
rs4711510 & 6 & $37,669,641$ & MDGA1 & 2558 & - & $2.1 \mathrm{E}-14$ & $3.5 \mathrm{E}-10$ & $1.2 \mathrm{E}-05$ & 0 & 0.73 \\
rs745527 & 1 & $111,745,975$ & CHI3L2 & 2581 & ++ & $3.0 \mathrm{E}-13$ & $4.8 \mathrm{E}-16$ & 0.16 & 93.2 & $1.3 \mathrm{E}-4$ \\
rs2384074 & 12 & $113,382,977$ & OAS1 & 38,394 & - & $9.5 \mathrm{E}-13$ & $2.2 \mathrm{E}-14$ & 0.076 & 90.5 & $1.2 \mathrm{E}-3$ \\
rs1365610 & 15 & $45,694,610$ & GATM & 84 & - & $1.1 \mathrm{E}-12$ & $4.8 \mathrm{E}-07$ & $3.1 \mathrm{E}-07$ & 0 & 0.32 \\
rs5742938 & 2 & $190,649,958$ & ASNSD1 & 123,846 & ++ & $1.1 \mathrm{E}-11$ & $7.2 \mathrm{E}-09$ & $2.9 \mathrm{E}-04$ & 0 & 0.51 \\
rs7549498 & 1 & $182,363,623$ & GLUL & 2281 & ++ & $2.2 \mathrm{E}-11$ & $3.9 \mathrm{E}-06$ & $6.5 \mathrm{E}-07$ & 22.1 & 0.26 \\
rs12460944 & 19 & $33,305,725$ & TDRD12 & 95,065 & ++ & $2.5 \mathrm{E}-11$ & $7.3 \mathrm{E}-08$ & $7.9 \mathrm{E}-05$ & 0 & 0.85 \\
rs34818 & 5 & $102,436,111$ & PPIP5K2 & 19,743 & - & $2.7 \mathrm{E}-11$ & $1.2 \mathrm{E}-07$ & $5.2 \mathrm{E}-05$ & 0 & 0.98 \\
rs7134391 & 12 & $113,366,691$ & OAS3 & 9467 & - & $2.1 \mathrm{E}-10$ & $1.9 \mathrm{E}-11$ & 0.092 & 86.8 & $5.9 \mathrm{E}-3$ \\
rs62391517 & 6 & $2,936,204$ & SERPINB1 & 93,963 & ++ & $3.7 \mathrm{E}-10$ & $1.8 \mathrm{E}-06$ & $4.8 \mathrm{E}-05$ & 0 & 0.76 \\
rs1628955 & 15 & $65,187,220$ & ANKDD1A & 16,882 & - & $1.2 \mathrm{E}-09$ & $2.7 \mathrm{E}-09$ & 0.025 & 70.8 & $6.4 \mathrm{E}-2$ \\
rs6136391 & 20 & $18,480,845$ & DTD1 & 87,693 & ++ & $1.6 \mathrm{E}-09$ & $1.1 \mathrm{E}-05$ & $2.9 \mathrm{E}-05$ & 0 & 0.53 \\
rs62383003 & 5 & $156,700,461$ & CYFIP2 & 7371 & - & $2.2 \mathrm{E}-09$ & $8.3 \mathrm{E}-06$ & $5.9 \mathrm{E}-05$ & 0 \\
rs754554 & 7 & $24,758,818$ & GSDME & 50,427 & ++ & $4.8 \mathrm{E}-09$ & $4.0 \mathrm{E}-10$ & 0.14 & 85.7 & 0.64 \\
\hline
\end{tabular}

been reported to be endogenous eQTLs in multiple tissues, but others (such as the TBC1D4 deQTL) seem to be more narrowly restricted to LCLs or blood. This is exemplified by the fact that some deQTL variants, such as the GATM deQTL, fall within regulatory elements in multiple cell types based on ChIP-seq data from the ENCODE project [28], while others may be restricted to regulatory elements active only in LCLs or similar blood cell types. Statins affect a wide-range of tissues, as evidenced by both the pleiotropy of statin benefit (i.e. reduction of circulating cholesterol and antiinflammatory properties), as well as the broadness of statin adverse effects (i.e. statin-induced diabetes, myopathy, etc.). Thus, the tissue-specificity (or lack of specificity) of individual deQTLs may be used to infer which (if any) of these statin effects they may impact.

Unsurprisingly, with the increased sample size in the meta-analysis, we discover more deQTLs than in the ethnic subset analyses. Importantly, we also observe a greater increase in precision of deQTL association

Table 4 eQTL, statin eQTL, and average eQTL relationships of deQTL associations

\begin{tabular}{|c|c|c|c|c|c|c|c|c|c|}
\hline Marker & Gene & $\begin{array}{l}\text { deQTL Meta } \\
\text { Dir }\end{array}$ & $\begin{array}{l}\text { deQTL Meta } \\
\text { P }\end{array}$ & $\begin{array}{l}\text { eQTL Meta } \\
\text { Dir }\end{array}$ & $\begin{array}{l}\text { eQTL Meta } \\
\text { P }\end{array}$ & $\begin{array}{l}\text { Statin eQTL Meta } \\
\text { Dir }\end{array}$ & $\begin{array}{l}\text { Statin eQTL } \\
\text { Meta P }\end{array}$ & $\begin{array}{l}\text { Ave eQTL Meta } \\
\text { Dir }\end{array}$ & $\begin{array}{l}\text { Ave eQTL } \\
\text { Meta P }\end{array}$ \\
\hline rs507901 & TBC1D4 & ++ & 7.30E-19 & ++ & $3.02 E-55$ & ++ & $3.30 \mathrm{E}-60$ & ++ & $9.41 \mathrm{E}-58$ \\
\hline rs47111510 & MDGA1 & - & 2.10E-14 & - & $2.02 E-102$ & - & 8.09E-101 & - & 3.41E-102 \\
\hline rs745527 & CHI3L2 & ++ & 3.00E-13 & ++ & $1.68 \mathrm{E}-29$ & ++ & 3.07E-30 & ++ & 5.64E-30 \\
\hline rs2384074 & OAS1 & - & $9.50 \mathrm{E}-13$ & ++ & 9.73E-02 & -+ & 2.81E-01 & -+ & 8.41E-01 \\
\hline rs1365610 & GATM & - & 1.10E-12 & ++ & $1.26 \mathrm{E}-03$ & ++ & $3.38 \mathrm{E}-01$ & ++ & 3.82E-02 \\
\hline rs5742938 & ASNSD1 & ++ & 1.10E-11 & - & $2.11 \mathrm{E}-47$ & - & $1.64 \mathrm{E}-26$ & - & 5.35E-40 \\
\hline rs7549498 & GLUL & ++ & 2.20E-11 & ++ & $1.58 \mathrm{E}-29$ & ++ & 4.31E-31 & ++ & $1.45 \mathrm{E}-30$ \\
\hline rs12460944 & TDRD12 & ++ & $2.50 \mathrm{E}-11$ & ++ & $4.12 \mathrm{E}-27$ & ++ & 1.73E-31 & ++ & 1.17E-29 \\
\hline rs34818 & PPIP5K2 & - & 2.70E-11 & ++ & $1.28 \mathrm{E}-76$ & ++ & 2.49E-65 & ++ & 7.48E-73 \\
\hline rs7134391 & OAS3 & - & 2.10E-10 & ++ & 2.29E-03 & ++ & 1.07E-01 & ++ & 1.95E-02 \\
\hline rs62391517 & $\begin{array}{l}\text { SERP } \\
\text { INBI }\end{array}$ & ++ & 3.70E-10 & ++ & $1.85 \mathrm{E}-38$ & ++ & 2.39E-42 & ++ & $6.01 \mathrm{E}-41$ \\
\hline rs1628955 & $\begin{array}{l}\text { ANKD } \\
\text { DIA }\end{array}$ & - & 1.20E-09 & - & $6.99 \mathrm{E}-97$ & - & 6.05E-97 & - & 9.30E-98 \\
\hline rs6136391 & DTD1 & ++ & 1.60E-09 & - & 5.89E-37 & - & 3.09E-25 & - & $1.06 \mathrm{E}-32$ \\
\hline rs62383003 & CYFIP2 & - & 2.20E-09 & - & 6.84E-08 & - & 2.43E-13 & - & 1.11E-10 \\
\hline rs754554 & GSDME & ++ & 4.80E-09 & - & 8.85E-36 & - & 1.70E-33 & - & 1.09E-34 \\
\hline
\end{tabular}




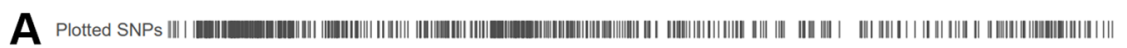

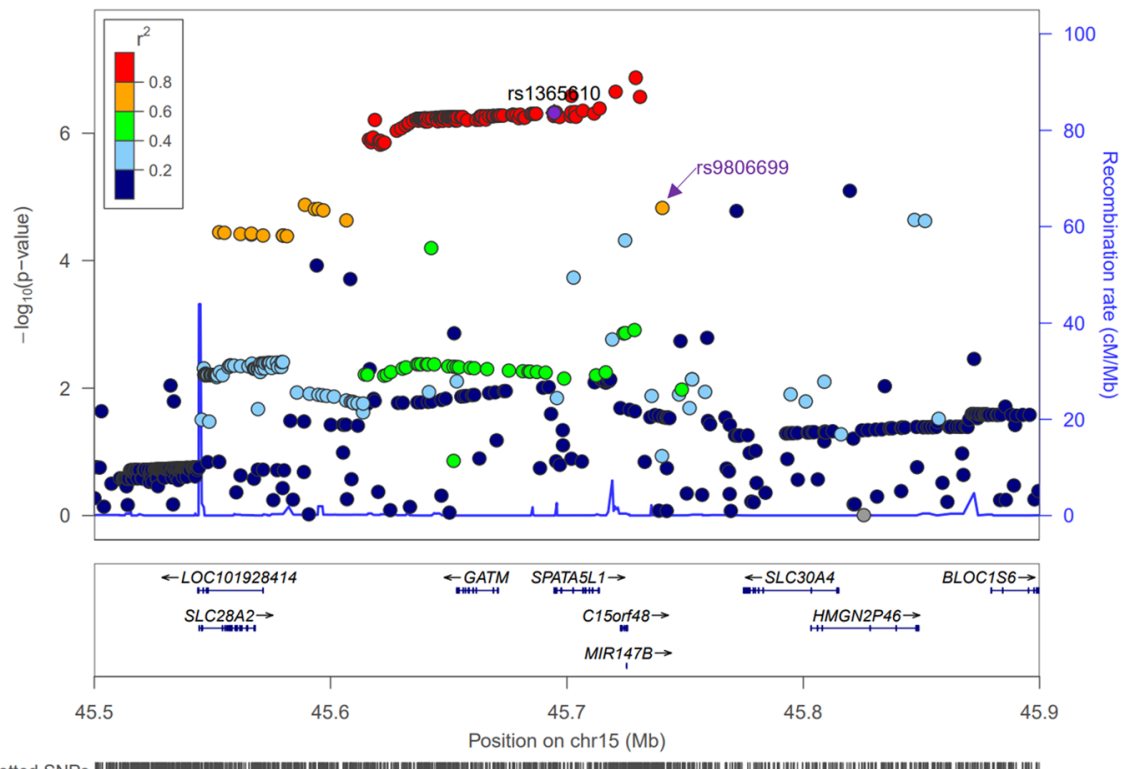

B

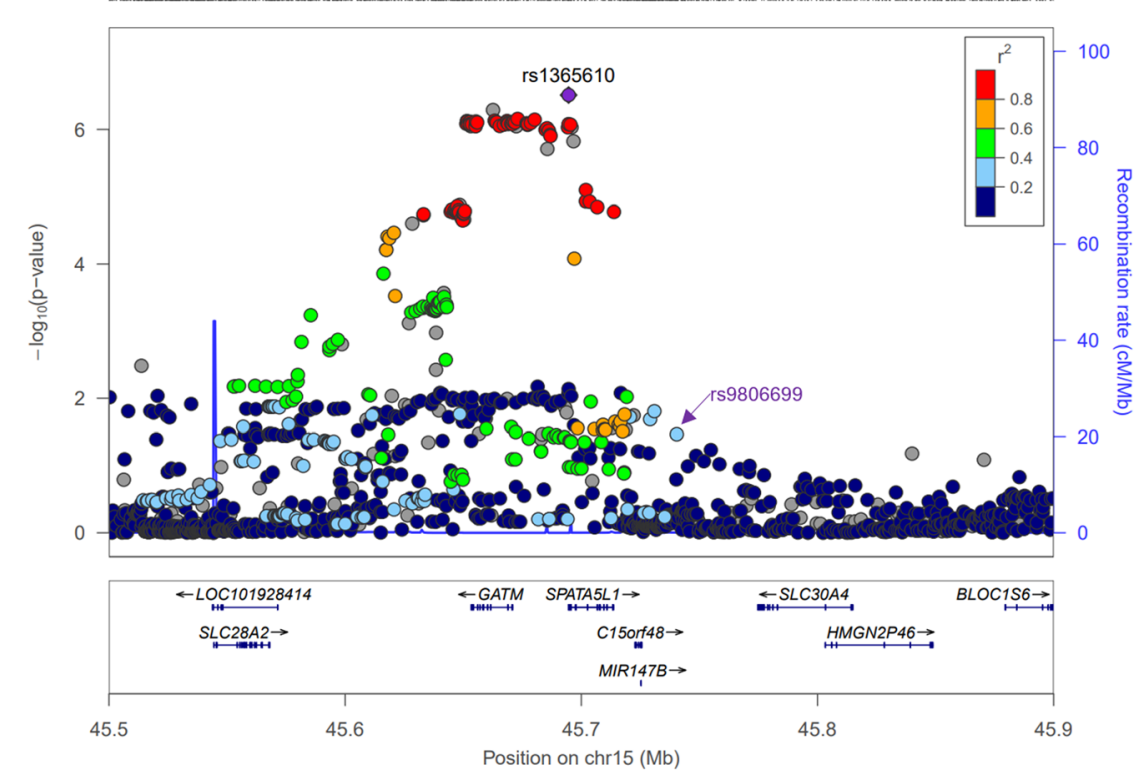

Fig. 9 LocusZoom plots of GATM deQTL results in each ancestry subset. a European ancestry deQTL using LD information from November 2014 1000 Genomes EUR (b) African American ancestry deQTL using LD information from November 20141000 Genomes AFR

signals in the meta-analysis compared to the European American subset analysis, which could be due in part to the reduced linkage disequilibrium between loci in the African American population [33], even though there are a relatively modest number of African Americans included in this study. In fact, the lead deQTL variants for GATM, GSDME, and ANKDD1A from the meta-analysis could themselves be functional since regulatory elements overlap their positions, unlike the corresponding lead deQTL variants from the European ancestry subset analysis.
Using a partially overlapping set of CAP European American LCLs, a deQTL was previously identified for glycine amidinotransferase (GATM), a creatine synthesis enzyme [18]. Here we show that the published GATM deQTL (rs9806699) is less likely to be functional than the lead deQTL variant (rs1365610) identified in the current analysis. Not only is rs1365610 located in a regulatory element just $84 \mathrm{bp}$ upstream of an alternate GATM TSS, but it is also the strongest GATM deQTL in the African American LCLs, while the rs9806699 association with GATM 


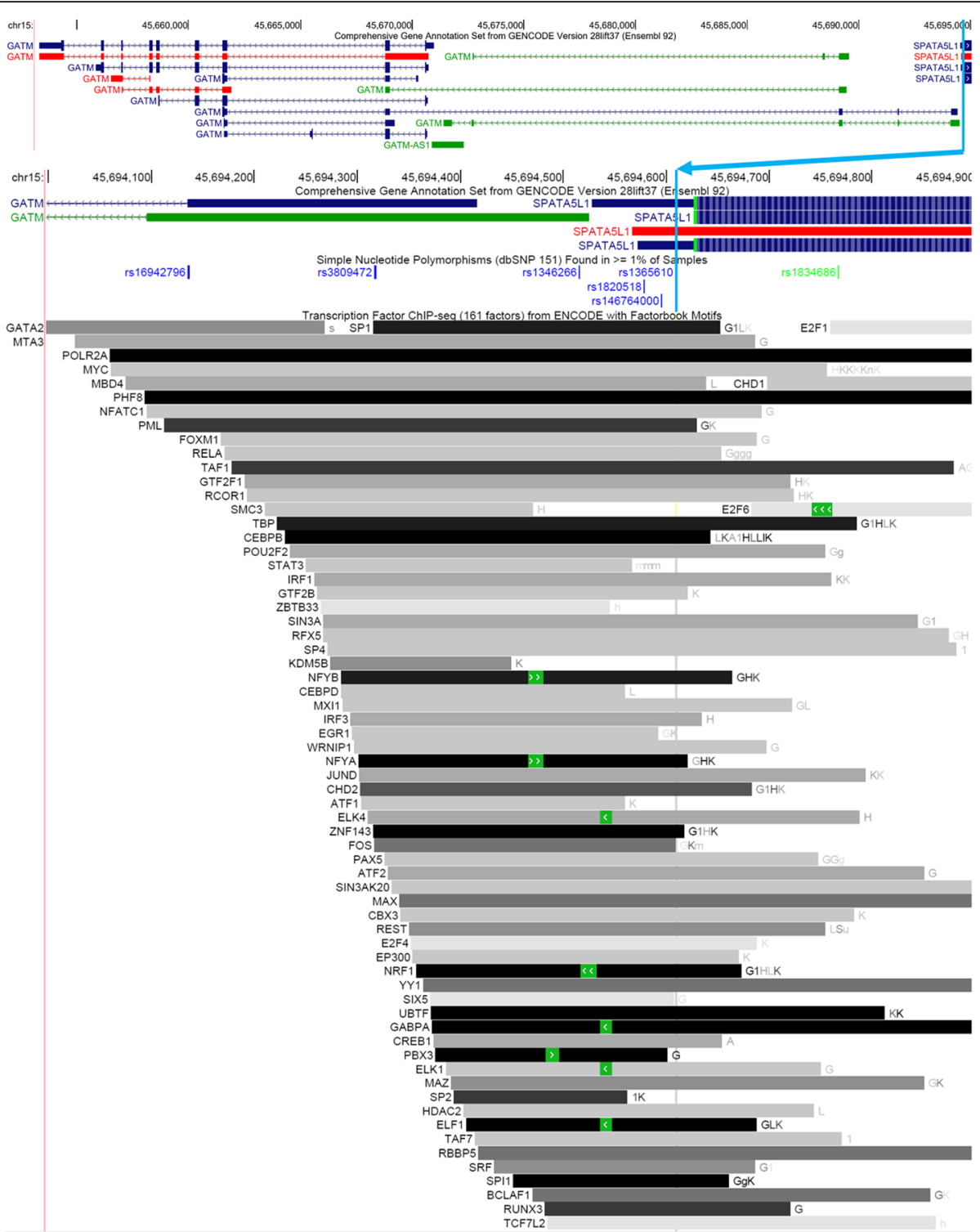

Fig. 10 Regulatory elements overlapping GATM lead deQTL from meta-analysis

statin response is only observed in European American LCLs.

In addition to GATM, which encodes a metabolically important enzyme, we identify deQTLs in other clinically significant genes. For instance, given reports that statins increase diabetes risk [4, 34, 35], it is interesting that we identify a deQTL for TBC1 domain family member $4(T B C 1 D 4)$, a gene which plays a role in glucose homeostasis and type 2 diabetes [36-38]. In addition, cellular gasdermin E (GSDME/DFNA5) expression levels help determine the type of cell death (i.e. pyroptosis or apoptosis) that is stimulated by chemotherapy drugs, with Gsdme knockout mice experiencing less side effects from the chemotherapy drug cisplatin than their wild type counterparts [39]. This is particularly interesting given that epidemiological studies have suggested that statin use reduces cancer-related mortality [40], and statins are well known to be cytotoxic in cellular models (reviewed in [41]), at least at supraphysiological levels.

$22^{\prime}-5^{\prime}$-oligoadenylate synthetase $1(O A S 1)$ and $2^{\prime}-5^{\prime}$ oligoadenylate synthetase 3 (OAS3) are important components of the innate immune system that are induced by interferon and can activate RNase L, which in turn can degrade cellular and viral RNAs and impair viral replication. Due to this activity, OAS1 has been a target of intense natural selection in humans [42]. Alternative splicing of OAS1 results in several isoforms with different enzymatic activity [43], and the splice site 


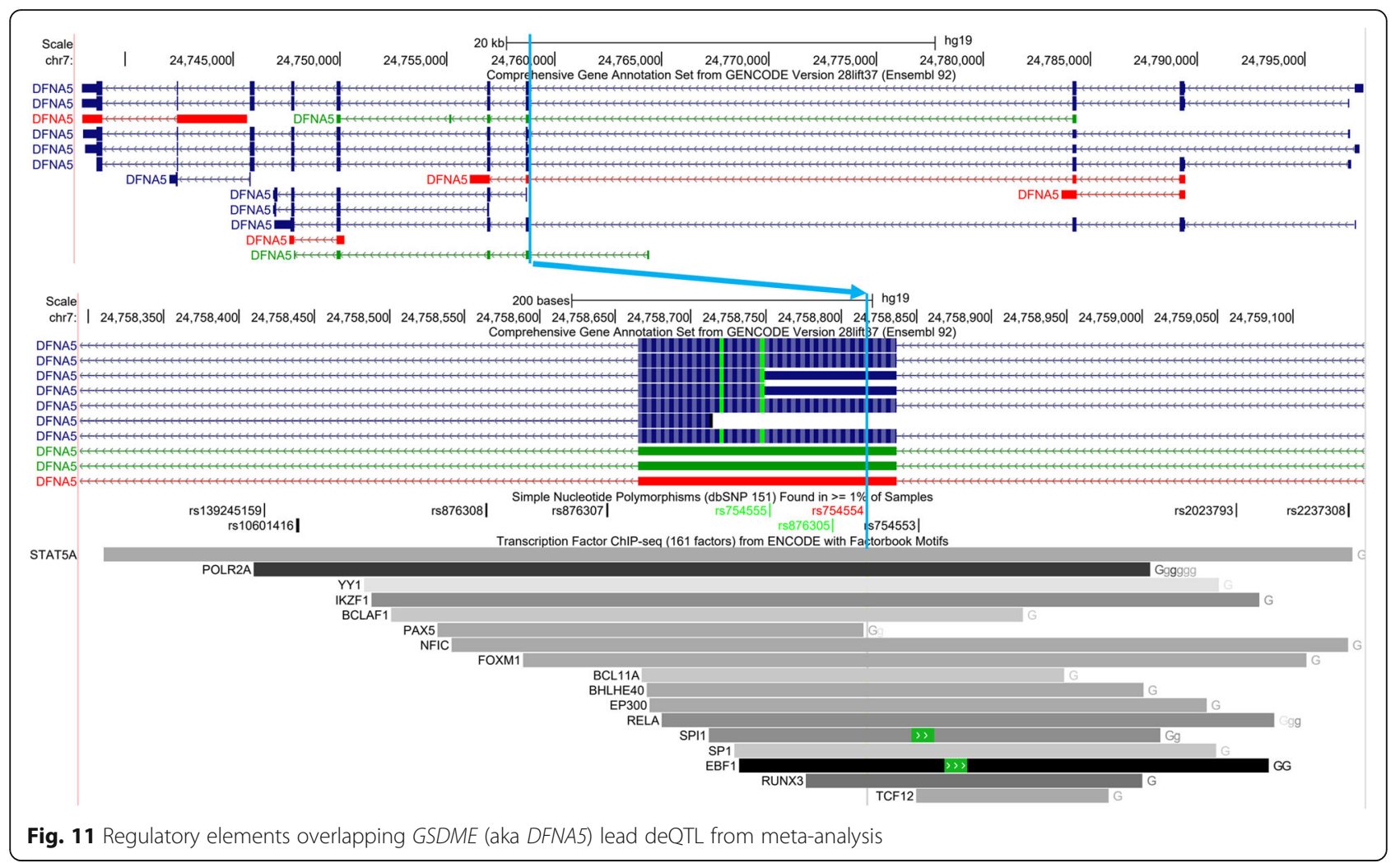

polymorphism rs10774671 has been associated with infection by viruses [44]. There is some evidence that statins have anti-viral activity against viruses such as Hepatitis C [45, 46], HIV-1 [47], poliovirus [48], and cytomegalovirus [49], though the mechanism(s) involved are poorly understood. In the future, it would be interesting to investigate whether the antiviral activity of statin treatment differs by $O A S 1 / 3$ deQTL genotype.

\section{Conclusions}

Overall, this study provides a resource of eQTLs identified in European ancestry and African American ancestry cell lines and identifies genetic variants that modulate the statin response of some clinically interesting genes. In the future, these differential eQTL variants could be incorporated into panels designed to predict benefits versus risk of statin therapy.

\section{Methods}

\section{Participants and genotyping}

This study uses genome-wide genotype and lymphoblastoid cell line (LCL) transcriptomic data derived from 412 of 944 Cholesterol and Pharmacogenetics (CAP) 40 $\mathrm{mg} /$ day 6 week simvastatin clinical trial participants (ClinicalTrials.gov ID: NCT00451828) [9]. Demographic and phenotypic characteristics of this participant subset are shown in Table 5. Self-reported white CAP participants were genotyped as previously described on one or more (Illumina HumanHap300, Human610Quad, custom iSelect and Cardio-Metabochip) platforms $[50,51]$, and self-reported black participants were genotyped on the Illumina HumanOmni2.5Exome and, for the majority of participants, the Cardio-Metabochip and Immunochip.

Table 5 Characteristics of European ancestry and African American ancestry CAP participants used in eQTL analyses

\begin{tabular}{lll}
\hline & African Americans & European Americans \\
\hline $\mathrm{N}$ & 153 & 259 \\
Gender & $53.6 \%$ Female & $47.9 \%$ Female \\
Age (years) & $53.7 \pm 12.8$ & $54.2 \pm 12.0$ \\
BMl & $30.1 \pm 6.0$ & $27.9 \pm 5.7$ \\
Smoker & $28.8 \%$ & $10.8 \%$ \\
${ }^{a}$ Total Cholesterol (mg/dl) & $204 \pm 36$ & $214 \pm 37$ \\
${ }^{a}$ LDL Cholesterol (mg/dl) & $129 \pm 35$ & $135 \pm 33$ \\
${ }^{a} H D L$ Cholesterol (mg/dl) & $55 \pm 17$ & $54 \pm 17$ \\
${ }^{a}$ Triglycerides (mg/dl) & $103 \pm 49$ & $125 \pm 67$ \\
$\%$ change TC & $-26 \pm 10 \%$ & $-28 \pm 9 \%$ \\
$\%$ change LDLC & $-40 \pm 13 \%$ & $-43 \pm 11 \%$ \\
\% change HDLC & $2 \pm 11 \%$ & $5 \pm 11 \%$ \\
\hline
\end{tabular}

Values are mean \pm SD. ${ }^{2}$ Values are prior to the start of statin treatment 


\section{Genotype imputation}

Prior to imputation, 3 sex mismatches, 2 related individuals, and 5 ancestry outliers were excluded from the subset of 422 CAP participants with both RNA-seq and genome-wide genotype data, and participants were divided into two groups (European American and African American) based on their genetic ancestry. Monomorphic, multi-allelic, and multi-mapping markers were excluded, except those that mapped to the $\mathrm{X}$ and $\mathrm{Y}$ chromosomes. Markers with greater than 5\% missingness or with significant deviations from Hardy-Weinberg equilibrium $(p<0.000001$ or $p<0.00001$ for European and African Americans, respectively) were also excluded. European Americans were imputed with the Haplotype Reference Consortium v1.1 reference panel [52] using minimac3 on the Michigan Imputation server [53]. African Americans were imputed with the 1000 genomes phase3v5 cosmopolitan reference panel [27] using $\mathrm{MaCH}$ Admix [54].

\section{RNA sequencing and analysis}

LCLs were established through Epstein-Barr virus (EBV) transformation of blood sample-derived lymphocytes as previously described [18]. Simvastatin (kindly provided by Merck Inc., Whitehouse Station, NJ) was activated by heating in ethanolic $\mathrm{NaOH}$ for $2 \mathrm{~h}$ at $50^{\circ} \mathrm{C}$, adjusting to $\mathrm{pH} 7.2$ with $\mathrm{HCl}$, and diluting to create a $10 \mathrm{mM}$ stock solution. The control buffer underwent the same procedure without simvastatin added. LCLs were exposed to $2 \mu \mathrm{M}$ simvastatin or control buffer for $24 \mathrm{~h}$, and total RNA was extracted as previously described [18]. PolyA-selected RNA was made into strand-specific [55] libraries for 100 or $101 \mathrm{bp}$ Illumina paired-end sequencing similar to previously described [56], except that this experiment included samples from an additional 262 LCLs in 2 additional library preparation and sequencing batches.

Using Tophatv2.0.4 [57], sequences were aligned to the human (hg19) and Epstein-Barr virus (EBV; NC_ 007605) genomes with Ensembl v67 [58] and EBV [59] transcriptome annotations, allowing 4 mismatches per read. Duplicate fragments were removed, and samples that did not meet quality control criteria (described previously [56]) were excluded. Fragments aligning to annotated genes were counted using HTSeq [60] and adjusted for library size and variance stabilized (roughly a $\log _{2}$ transformation) using DESeq2 [61]. Gene expression changes (deltas) were calculated by subtracting endogenous from statin-treated variance stabilized expression levels.

For downstream eQTL analyses, gene expression levels or changes were adjusted for potential confounders using probabilistic estimation of expression residuals (PEER) [62]. For endogenous, statin-treated, and average expression levels, we used $\mathrm{K}=40$ hidden factors and a mean expression covariate. This appeared to be a sufficient number of hidden factors, because very little expression level variance was explained by factors 13-40. For statin-induced gene expression changes, we used $\mathrm{K}=6$ and 7 measured covariates (delta fraction of fragments aligned, delta fraction of duplicate fragments, delta fraction of ribosomal fragments, delta fraction of EBV fragments, delta fraction of fragments aligning to annotated mRNA transcripts, delta fraction of fragments aligning to the annotated strand, and delta $5^{\prime} \rightarrow 3^{\prime}$ bias). Additional hidden factors for this analysis would have been redundant, since pilot analyses indicated that any additional hidden factors were strongly correlated to one of the first six (Spearman correlation $>0.9, p<1 \times$ $\left.10^{-74}\right)$. Since the changes in gene expression were calculated between samples from genetically identical cell lines processed in the same experimental batches, it is expected that fewer hidden factors were necessary for the gene expression change analysis compared to the expression level analyses. For OAS1 splicing analyses, junction-spanning sequence fragments were quantified using Leafcutter [63].

\section{eQTL analyses}

PEER normalized gene expression levels or changes were tested for association with well-imputed (imputation Rsq $\geq 0.5$ ) common ( $\geq 3 \%$ MAF in European Americans or $\geq 5 \%$ MAF in African Americans) genetic variants within $1 \mathrm{Mb}$ of the transcription start site (in cis) using FastQTL [22] in the European and African American subsets separately. Sex and the first three ancestry principal components were included as covariates, and gene expression phenotypes were normalized prior to analysis. To adjust for testing multiple variants per gene, 100 to 100,000 adaptive permutations were conducted per gene for endogenous, statin-treated, and average eQTL analyses, while 100 to 1,000,000 were conducted for differential eQTL analyses. The most significant eQTL association per gene was retained, and these $p$-values were false discovery rate (FDR)-adjusted to account for the number of genes tested.

eQTL meta-analyses incorporating results from both European and African Americans were conducted in METAL [23], using p-value, direction of effect, and sample size as input. Heterogeneity between ethnic subsets was also evaluated. A conservative threshold of $5.78 \times 10^{-9}$ was used for significance of the deQTL meta-analysis based on $\leq 13,841$ genes tested and 625 independent markers per $2 \mathrm{Mb}$ of genome. (One million independent markers per genome divided by $3200 \mathrm{Mb} /$ genome would estimate 312.5 independent markers per $\mathrm{Mb}$.) 


\section{Supplementary information}

Supplementary information accompanies this paper at https://doi.org/10. 1186/s12864-020-06966-4.

Additional file 1: Table S1. Lead endogenous eQTLs per gene in LCLS from European ancestry subset.

Additional file 2: Table S2. Lead endogenous eQTLs per gene in LCLS from African American ancestry subset.

Additional file 3: Table S3. Lead LCL endogenous eQTLs per gene from meta-analysis with $p<0.00001$.

Additional file 4: Table S4. Lead statin-treated eQTLs per gene in LCLS from European ancestry subset.

Additional file 5: Table S5. Lead statin-treated eQTLs per gene in LCLS from African American ancestry subset.

Additional file 6: Table S6. Lead statin-treated LCL eQTLs per gene from meta-analysis with $p<0.00001$.

Additional file 7: Table S7. Lead European ancestry eQTL for average of endogenous and statin-treated LCL gene expression levels.

Additional file 8: Table S8. Lead African American ancestry eQTL for average of endogenous and statin-treated LCL gene expression levels.

Additional file 9: Table S9. Lead eQTL for average of endogenous and statin-treated LCL gene expression levels from meta-analysis with $p<$ 0.00001 .

Additional file 10: Table S10. eQTL relationships in public datasets of our deQTL associations.

\section{Abbreviations}

deQTL: Differential expression quantitative trait locus; LCL: Lymphoblastoid cell line; CAP: Cholesterol and Pharmacogenetics; eQTL: Expression quantitative trait locus; LDL-C: Low-density lipoprotein cholesterol; GWAS: Genome-wide association study; GTEx: Genotype-Tissue Expression; FDR: False discovery rate; PEER: Probabilistic estimation of expression residuals; EBV: Epstein-Barr virus; TBC1D4: TBC1 domain family member 4; MDGA1: MAM domain containing glycosylphosphatidylinositol anchor 1; CHI3L2: Chitinase 3 like 2; OAS1: 2'-5'-oligoadenylate synthetase 1; GATM: Glycine amidinotransferase; ASNSD1: Asparagine synthetase domain containing 1; GLUL: Glutamate-ammonia ligase; TDRD12: Tudor domain containing 12; PPIP5K2: Diphosphoinositol pentakisphosphate kinase 2; OAS3: 2'-5'-oligoadenylate synthetase 3; SERPINB1: Serpin family B member 1; ANKDD1A: Ankyrin repeat and death domain containing 1A; DTD1: Daminoacyl-tRNA deacylase 1; CYFIP2: Cytoplasmic FMR1 interacting protein 2; GSDME: Gasdermin E; DFNA5: Deafness, autosomal dominant 5

\section{Acknowledgements}

We thank Kristen Stevens, Devesh Naidoo, and other personnel who cultured and statin-exposed the LCLs and extracted samples for this project. We thank the Northwest Genomics Center for generating the majority of the genotype and sequence data for this project. We thank the CAP participants for their participation. An abstract based on this work was previously presented as a poster at the 2016 American Society of Human Genetics (ASHG) meeting.

\section{Authors' contributions}

E.T. contributed to conceptualizing the work, performed all analyses, and drafted the manuscript. M.W.M. and R.M.K. conceptualized the work and edited the manuscript. Y.I.C. and J.I.R. helped to create the LCLS and provided feedback on the manuscript. All authors read and approved the final manuscript.

\section{Funding}

This project was supported by NIH U19 HL069757, AHA 15POST21880006, NIH P50 GM115318, and NIH R01 HL139902. This study was also supported in part by the NIH Pharmacogenomics Research Network (PGRN) RNA Sequencing Project, the National Center for Advancing Translational Sciences, CTSI grant ULTR001881, and the National Institute of Diabetes and Digestive and Kidney Disease Diabetes Research Center (DRC) grant DK063491 to the Southern California Diabetes Endocrinology Research
Center. The funders had no role in study design, data collection and analysis, data interpretation, or manuscript writing.

\section{Availability of data and materials}

CAP subject genotype and LCL RNA-seq data used in this study are in the database of Genotypes and Phenotypes (dbGaP) under phs000481.v3.p2. All eQTL results are being deposited into the genome-wide repository of associations between SNPs and phenotypes (GRASP) database [64].

\section{Ethics approval and consent to participate}

Written informed consent was obtained from participants and approved by institutional review boards at the University of California Los Angeles and San Francisco General Hospital.

\section{Consent for publication}

Not applicable.

\section{Competing interests}

The authors declare that they have no competing interests.

\section{Author details}

${ }^{1}$ Department of Pediatrics, University of California San Francisco, Oakland, CA, USA. ${ }^{2}$ Department of Pediatrics, The Institute for Translational Genomics and Population Sciences, Los Angeles Biomedical Research Institute at Harbor-UCLA Medical Center, Torrance, CA, USA. ${ }^{3}$ Departments of Pediatrics and Medicine, The Institute for Translational Genomics and Population Sciences, Los Angeles Biomedical Research Institute at Harbor-UCLA Medical Center, Torrance, CA, USA. ${ }^{4}$ Departments of Pediatrics and Medicine, University of California San Francisco, Oakland, CA, USA.

Received: 14 November 2019 Accepted: 3 August 2020 Published online: 12 August 2020

\section{References}

1. Baigent C, Keech A, Kearney PM, Blackwell L, Buck G, Pollicino C, et al. Efficacy and safety of cholesterol-lowering treatment: prospective metaanalysis of data from 90,056 participants in 14 randomised trials of statins. Lancet. 2005;366(9493):1267-78.

2. Bedi O, Dhawan V, Sharma PL, Kumar P. Pleiotropic effects of statins: new therapeutic targets in drug design. Naunyn Schmiedeberg's Arch Pharmacol. 2016;389(7):695-712.

3. Harper CR, Jacobson TA. The broad spectrum of statin myopathy: from myalgia to rhabdomyolysis. Curr Opin Lipidol. 2007;18(4):401-8.

4. Sattar N, Preiss D, Murray HM, Welsh P, Buckley BM, de Craen AJ, et al. Statins and risk of incident diabetes: a collaborative meta-analysis of randomised statin trials. Lancet. 2010;375(9716):735-42.

5. Mangravite LM, Thorn CF, Krauss RM. Clinical implications of pharmacogenomics of statin treatment. Pharm J. 2006;6(6):360-74.

6. Chasman DI, Giulianini F, Macfadyen J, Barratt BJ, Nyberg F, Ridker PM. Genetic determinants of statin-induced low-density lipoprotein cholesterol reduction: the justification for the use of statins in prevention: an intervention trial evaluating Rosuvastatin (JUPITER) trial. Circ Cardiovasc Genet. 2012;5(2):257-64. https://doi.org/10.1161/CIRCGENETICS.111.961144 PubMed PMID: 22331829.

7. Deshmukh HA, Colhoun HM, Johnson T, McKeigue PM, Betteridge DJ, Durrington PN, et al. Genome-wide association study of genetic determinants of $L D L-c$ response to atorvastatin therapy: importance of Lp(a). J Lipid Res. 2012:53(5):1000-11.

8. Postmus I, Trompet S, Deshmukh HA, Barnes MR, Li X, Warren HR, et al. Pharmacogenetic meta-analysis of genome-wide association studies of LDL cholesterol response to statins. Nat Commun. 2014;5:5068.

9. Simon JA, Lin F, Hulley SB, Blanche PJ, Waters D, Shiboski S, et al. Phenotypic predictors of response to simvastatin therapy among AfricanAmericans and Caucasians: the cholesterol and Pharmacogenetics (CAP) study. Am J Cardiol. 2006;97(6):843-50.

10. Nicolae DL, Gamazon E, Zhang W, Duan S, Dolan ME, Cox NJ. Traitassociated SNPs are more likely to be eQTLs: annotation to enhance discovery from GWAS. PLoS Genet. 2010;6(4):e1000888.

11. Consortium GT, Laboratory DA. Coordinating center -analysis working G, statistical methods groups-analysis working G, enhancing Gg, fund NIHC, 
et al. genetic effects on gene expression across human tissues. Nature. 2017;550(7675):204-13.

12. Motsinger-Reif AA, Jorgenson E, Relling MV, Kroetz DL, Weinshilboum R, Cox NJ, et al. Genome-wide association studies in pharmacogenomics: successes and lessons. Pharmacogenet Genomics. 2013;23(8):383-94.

13. Lee MN, Ye C, Villani AC, Raj T, Li W, Eisenhaure TM, et al. Common genetic variants modulate pathogen-sensing responses in human dendritic cells. Science. 2014;343(6175):1246980.

14. Caliskan M, Baker SW, Gilad Y, Ober C. Host genetic variation influences gene expression response to rhinovirus infection. PLoS Genet. 2015;11(4): e1005111.

15. Barreiro LB, Tailleux L, Pai AA, Gicquel B, Marioni JC, Gilad Y. Deciphering the genetic architecture of variation in the immune response to mycobacterium tuberculosis infection. Proc Natl Acad Sci U S A. 2012;109(4): 1204-9.

16. Fairfax BP, Humburg P, Makino S, Naranbhai V, Wong D, Lau E, et al. Innate immune activity conditions the effect of regulatory variants upon monocyte gene expression. Science. 2014;343(6175):1246949.

17. Kita R, Fraser HB. Local adaptation of sun-exposure-dependent gene expression regulation in human skin. PLoS Genet. 2016;12(10):e1006382.

18. Mangravite LM, Engelhardt BE, Medina MW, Smith JD, Brown CD, Chasman DI, et al. A statin-dependent QTL for GATM expression is associated with statin-induced myopathy. Nature. 2013;502(7471):377-80 Epub 2013/09/03.

19. Knowles DA, Davis JR, Edgington $H$, Raj A, Fave MJ, Zhu X, et al. Allelespecific expression reveals interactions between genetic variation and environment. Nat Methods. 2017;14(7):699-702.

20. Brown MS, Goldstein JL. The SREBP pathway: regulation of cholesterol metabolism by proteolysis of a membrane-bound transcription factor. Cell. 1997:89(3):331-40.

21. Medina MW, Gao F, Ruan W, Rotter Jl, Krauss RM. Alternative splicing of 3hydroxy-3-methylglutaryl coenzyme a reductase is associated with plasma low-density lipoprotein cholesterol response to simvastatin. Circulation. 2008;118(4):355-62.

22. Ongen H, Buil A, Brown AA, Dermitzakis ET, Delaneau O. Fast and efficient QTL mapper for thousands of molecular phenotypes. Bioinformatics. 2016; 32(10):1479-85.

23. Willer CJ, Li Y, Abecasis GR. METAL: fast and efficient meta-analysis of genomewide association scans. Bioinformatics. 2010;26(17):2190-1.

24. Oliveros JC. Venny. An interactive tool for comparing lists with Venn's diagrams.: http://bioinfogp.cnb.csic.es/tools/venny/index.html; 2007-2015.

25. Lappalainen T, Sammeth M, Friedlander MR, PA TH, Monlong J, Rivas MA, et al. Transcriptome and genome sequencing uncovers functional variation in humans. Nature. 2013;501(7468):506-11.

26. Westra HJ, Peters MJ, Esko T, Yaghootkar H, Schurmann C, Kettunen J, et al. Systematic identification of trans eQTLs as putative drivers of known disease associations. Nat Genet. 2013;45(10):1238-43.

27. Genomes Project C, Auton A, Brooks LD, Durbin RM, Garrison EP, Kang HM, et al. A global reference for human genetic variation. Nature. 2015; 526(7571):68-74

28. Consortium EP. An integrated encyclopedia of DNA elements in the human genome. Nature. 2012;489(7414):57-74.

29. Kent WJ, Sugnet CW, Furey TS, Roskin KM, Pringle TH, Zahler AM, et al. The human genome browser at UCSC. Genome Res. 2002;12(6):996-1006.

30. Boyle AP, Hong EL, Hariharan M, Cheng Y, Schaub MA, Kasowski M, et al. Annotation of functional variation in personal genomes using RegulomeDB. Genome Res. 2012;22(9):1790-7.

31. Hoffmann TJ, Theusch E, Haldar T, Ranatunga DK, Jorgenson E, Medina MW, et al. A large electronic-health-record-based genome-wide study of serum lipids. Nat Genet. 2018;50(3):401-13.

32. Willer CJ, Schmidt EM, Sengupta S, Peloso GM, Gustafsson S, Kanoni S, et al. Discovery and refinement of loci associated with lipid levels. Nat Genet. 2013;45(11):1274-83

33. Peprah E, Xu H, Tekola-Ayele F, Royal CD. Genome-wide association studies in Africans and African Americans: expanding the framework of the genomics of human traits and disease. Public Health Genomics. 2015;18(1): 40-51.

34. Ridker PM, Danielson E, Fonseca FA, Genest J, Gotto AM Jr, Kastelein JJ, et al. Rosuvastatin to prevent vascular events in men and women with elevated C-reactive protein. N Engl J Med. 2008;359(21):2195-207.

35. Goodarzi MO, Li X, Krauss RM, Rotter JI, Chen YD. Relationship of sex to diabetes risk in statin trials. Diabetes Care. 2013;36(7):e100-1.
36. Sano H, Kane S, Sano E, Miinea CP, Asara JM, Lane WS, et al. Insulinstimulated phosphorylation of a Rab GTPase-activating protein regulates GLUT4 translocation. J Biol Chem. 2003;278(17):14599-602.

37. Moltke I, Grarup N, Jorgensen ME, Bjerregaard P, Treebak JT, Fumagalli M, et al. A common Greenlandic TBC1D4 variant confers muscle insulin resistance and type 2 diabetes. Nature. 2014;512(7513):190-3.

38. Wang HY, Ducommun S, Quan C, Xie B, Li M, Wasserman DH, et al. AS160 deficiency causes whole-body insulin resistance via composite effects in multiple tissues. Biochem J. 2013;449(2):479-89.

39. Wang Y, Gao W, Shi X, Ding J, Liu W, He H, et al. Chemotherapy drugs induce pyroptosis through caspase-3 cleavage of a gasdermin. Nature. 2017 547(7661):99-103.

40. Nielsen SF, Nordestgaard BG, Bojesen SE. Statin use and reduced cancerrelated mortality. N Engl J Med. 2012;367(19):1792-802.

41. Wong WW, Dimitroulakos J, Minden MD, Penn LZ. HMG-CoA reductase inhibitors and the malignant cell: the statin family of drugs as triggers of tumor-specific apoptosis. Leukemia. 2002;16(4):508-19.

42. Ferguson W, Dvora S, Fikes RW, Stone AC, Boissinot S. Long-term balancing selection at the antiviral gene OAS1 in Central African chimpanzees. Mol Biol Evol. 2012;29(4):1093-103.

43. Bonnevie-Nielsen V, Field LL, Lu S, Zheng DJ, Li M, Martensen PM, et al. Variation in antiviral 2',5'-oligoadenylate synthetase (2'5'AS) enzyme activity is controlled by a single-nucleotide polymorphism at a splice-acceptor site in the OAS1 gene. Am J Hum Genet. 2005;76(4):623-33.

44. Lim JK, Lisco A, McDermott DH, Huynh L, Ward JM, Johnson B, et al. Genetic variation in OAS1 is a risk factor for initial infection with West Nile virus in man. PLoS Pathog. 2009:5(2):e1000321.

45. Ikeda M, Abe K, Yamada M, Dansako H, Naka K, Kato N. Different anti-HCV profiles of statins and their potential for combination therapy with interferon. Hepatology. 2006:44(1):117-25.

46. Zheng YX, Zhou PC, Zhou RR, Fan XG. The benefit of statins in chronic hepatitis $C$ patients: a systematic review and meta-analysis. Eur J Gastroenterol Hepatol. 2017;29(7):759-66.

47. Giguere JF, Tremblay MJ. Statin compounds reduce human immunodeficiency virus type 1 replication by preventing the interaction between virion-associated host intercellular adhesion molecule 1 and its natural cell surface ligand LFA-1. J Virol. 2004;78(21):12062-5.

48. Liu S, Rodriguez AV, Tosteson MT. Role of simvastatin and methyl-betacyclodextrin [corrected] on inhibition of poliovirus infection. Biochem Biophys Res Commun. 2006;347(1):51-9.

49. Potena L, Frascaroli G, Grigioni F, Lazzarotto T, Magnani G, Tomasi L, et al. Hydroxymethyl-glutaryl coenzyme a reductase inhibition limits cytomegalovirus infection in human endothelial cells. Circulation. 2004; 109(4):532-6.

50. Barber MJ, Mangravite LM, Hyde CL, Chasman DI, Smith JD, McCarty CA et al. Genome-wide association of lipid-lowering response to statins in combined study populations. PLoS One. 2010;5(3):e9763.

51. Theusch E, Medina MW, Rotter Jl, Krauss RM. Ancestry and other genetic associations with plasma PCSK9 response to simvastatin. Pharmacogenet Genomics. 2014;24(10):492-500.

52. McCarthy S, Das S, Kretzschmar W, Delaneau O, Wood AR, Teumer A, et al. A reference panel of 64,976 haplotypes for genotype imputation. Nat Genet. 2016:48(10):1279-83.

53. Das S, Forer L, Schonherr S, Sidore C, Locke AE, Kwong A, et al. Nextgeneration genotype imputation service and methods. Nat Genet. 2016; 48(10):1284-7.

54. Liu EY, Li M, Wang W, Li Y. MaCH-admix: genotype imputation for admixed populations. Genet Epidemiol. 2013;37(1):25-37.

55. Parkhomchuk D, Borodina T, Amstislavskiy V, Banaru M, Hallen L, Krobitsch S, et al. Transcriptome analysis by strand-specific sequencing of complementary DNA. Nucleic Acids Res. 2009;37(18):e123. https://doi.org/10.1093/nar/gkp596 PubMed PMID: 19620212; PubMed Central PMCID: PMC2764448.

56. Theusch E, Kim K, Stevens K, Smith JD, Chen YI, Rotter Jl, et al. Statininduced expression change of INSIG1 in lymphoblastoid cell lines correlates with plasma triglyceride statin response in a sex-specific manner. Pharm J. 2017;17(3):222-9.

57. Kim D, Pertea G, Trapnell C, Pimentel H, Kelley R, Salzberg SL. TopHat2: accurate alignment of transcriptomes in the presence of insertions, deletions and gene fusions. Genome Biol. 2013;14(4):R36.

58. Zerbino DR, Achuthan P, Akanni W, Amode MR, Barrell D, Bhai J, et al. Ensembl 2018. Nucleic Acids Res. 2018;46(D1):D754-D61. 
59. Arvey A, Tempera I, Tsai K, Chen HS, Tikhmyanova N, Klichinsky M, et al. An atlas of the Epstein-Barr virus transcriptome and epigenome reveals hostvirus regulatory interactions. Cell Host Microbe. 2012;12(2):233-45.

60. Anders S, Pyl PT, Huber W. HTSeq--a Python framework to work with highthroughput sequencing data. Bioinformatics. 2015;31(2):166-9.

61. Love Ml, Huber W, Anders S. Moderated estimation of fold change and dispersion for RNA-seq data with DESeq2. Genome Biol. 2014;15(12):550.

62. Stegle O, Parts L, Durbin R, Winn J. A Bayesian framework to account for complex non-genetic factors in gene expression levels greatly increases power in eQTL studies. PLoS Comput Biol. 2010;6(5):e1000770.

63. Li Yl, Knowles DA, Humphrey J, Barbeira AN, Dickinson SP, Im HK, et al. Annotation-free quantification of RNA splicing using LeafCutter. Nat Genet. 2018;50(1):151-8.

64. Eicher JD, Landowski C, Stackhouse B, Sloan A, Chen W, Jensen N, et al. GRASP V2.0: an update on the genome-wide repository of associations between SNPs and phenotypes. Nucleic Acids Res. 2015;43(Database issue): D799-804.

\section{Publisher's Note}

Springer Nature remains neutral with regard to jurisdictional claims in published maps and institutional affiliations.

Ready to submit your research? Choose BMC and benefit from:

- fast, convenient online submission

- thorough peer review by experienced researchers in your field

- rapid publication on acceptance

- support for research data, including large and complex data types

- gold Open Access which fosters wider collaboration and increased citations

- maximum visibility for your research: over $100 \mathrm{M}$ website views per year

At BMC, research is always in progress.

Learn more biomedcentral.com/submissions 